\title{
On a stochastically grain-discretised model for 2D/3D temperature mapping prediction in grinding
}

\begin{abstract}
Excessive grinding heat might probably lead to unwanted heat damages of workpiece materials, most previous studies on grinding heat/temperature, however, assumed the wheel-workpiece contact zone as a moving band heat source, which might be not appropriate enough to capture the realistic situation in grinding. To address this, grinding temperature domain has been theoretically modeled in this paper by using a stochastically grain-discretised temperature model (SGDTM) with the consideration of grain-workpiece micro interactions (i.e. rubbing, ploughing and cutting), and the full 2D/3D temperature maps with highly-localised thermal information, even at the grain scale (i.e. with the thermal impacts induced by each individual grain), has been presented for the first time. To validate theoretical maps, a new methodological approach to capture 2D/3D temperature maps based on an array of sacrificial thermocouples have also been proposed. Experimental validation has indicated that the grinding temperature calculated by SGDTM showed a reasonable agreement with the experimental one in terms of both $1 \mathrm{D}$ temperature signals (i.e. the signals that are captured at a specific location within the grinding zone) and the 2D/3D temperature maps of the grinding zone, proving the feasibility and the accuracy of SGDTM. This study has also proved that, as expected, the heat fluxes are neither uniformly-distributed along the wheel width direction nor continuous along the workpiece feed direction. The proposed SGDTM and the temperature measurement technique are not only anticipated to be powerful to provide the basis for the prevention of grinding thermal damage (e.g. grinding burns, grinding annealing and rehardening), but also expected to be meaningful to enhance the existing understanding of grinding heat/temperature than using the common approach depending on the single thermocouple technique.
\end{abstract}

Keywords: grinding; temperature mapping; grain-workpiece interaction; thermocouple array; temperature model

\begin{tabular}{|c|c|c|c|}
\hline \\
\hline$a_{p}$ & depth of cut $(\mathrm{m})$ & $q_{\text {stages }}$ & $\begin{array}{l}\text { total heat flux generated by all the grains } \\
\text { in the rubbing, ploughing and cutting } \\
\text { stages when stages are rubbing, } \\
\text { ploughing and cutting }\left(\mathrm{W} \cdot \mathrm{m}^{-2}\right)\end{array}$ \\
\hline$A_{\max , a v}$ & $\begin{array}{l}\text { maximum and average amplitude of a spike } \\
\text { temperature signal (K) (see Fig.12) }\end{array}$ & $r_{e}^{(k)}$ & effective contact radius of grain $k(\mathrm{~m})$ \\
\hline$b$ & grinding wheel width $(\mathrm{m})$ & $S_{g p_{-} t_{i}}^{\text {stages }}$ & $\begin{array}{l}\text { total penetration area of all the grains in } \\
\text { the rubbing, ploughing and cutting stage } \\
\text { when stages are rubbing, ploughing and } \\
\left.\text { cutting }\left(\mathrm{m}^{2}\right) \text { (see Fig. } 4 \mathrm{~b}\right)\end{array}$ \\
\hline$C_{p}$ & $\begin{array}{l}\text { specific heat capacity of workpiece material } \\
\left(\mathrm{J} \cdot \mathrm{kg}^{-1} \cdot \mathrm{K}^{-1}\right)\end{array}$ & $S_{g p_{-} t_{i}}^{(k)}$ & $\begin{array}{l}\text { grain penetration area of grain } k \text { at the } \\
\text { time } t_{i}\left(\mathrm{~m}^{2}\right) \text { (see Fig. } 4 \mathrm{~b} \text { ) }\end{array}$ \\
\hline$d_{g}^{(k)}$ & grain $k$ diameter $(\mathrm{m})$ & $S_{\max , a v}$ & $\begin{array}{l}\text { maximum and average time interval } \\
\text { between two adjacent spike temperature } \\
\text { signals (s) (see Fig.12) }\end{array}$ \\
\hline$d_{\text {gmax,gmin }}$ & $\begin{array}{l}\text { maximum and minimum grain diameters } \\
\text { among all the grains of a grinding wheel }(\mathrm{m})\end{array}$ & $T_{c s, c e}$ & $\begin{array}{l}\text { coolant temperature at the starting and } \\
\text { ending of the grinding process }(\mathrm{K})\end{array}$ \\
\hline$d_{s}$ & outer diameter of a grinding wheel $(\mathrm{m})$ & $T_{m p}$ & $\begin{array}{l}\text { melting temperature of workpiece materia } \\
\text { (K) }\end{array}$ \\
\hline$E_{S, w}$ & $\begin{array}{l}\text { elasticity modulus of a grinding wheel and of } \\
\text { workpiece materials }\left(\mathrm{N} \cdot \mathrm{m}^{-2}\right)\end{array}$ & $T_{o}$ & ambient temperature $(\mathrm{K})$ \\
\hline$F_{n, t}$ & normal and tangential grinding force $(\mathrm{N})$ & $T\left(x, y, z, t_{i}\right)$ & $\begin{array}{l}\text { temperature of the position }(x, y, z) \text { at the } \\
\text { time } t_{i}(\mathrm{~K})\end{array}$ \\
\hline$F_{n, t}{ }^{\prime}$ & normal and tangential grinding force per unit & $\operatorname{Tmax}_{t=t_{i}}^{\text {theor, exper }}$ & maximum temperature within the grinding \\
\hline
\end{tabular}




\begin{tabular}{|c|c|c|c|}
\hline & wheel width $\left(\mathrm{N} \cdot \mathrm{m}^{-1}\right)$ & & zone at the time $t_{i}$ calculated by SGDTM \\
\hline$h_{\text {cool }}$ & $\begin{array}{l}\text { convective heat transfer coefficient of } \\
\text { coolants }\left(\mathrm{W} \cdot \mathrm{m}^{-2} \cdot \mathrm{K}^{-1}\right)\end{array}$ & $t_{80,60,40}$ & $\begin{array}{l}\text { timespan of } 80 \%, 60 \% \text { and } 40 \% \text { maximum } \\
\text { value of the upper envelope of a } \\
\text { temperature signal (s) (see Fig.12) }\end{array}$ \\
\hline$h_{g p_{-} t_{i}}^{(k)}$ & $\begin{array}{l}\text { grain penetration depth of grain } k \text { at the } \\
\text { time } t_{i}(\mathrm{~m}) \text { (see Fig.4b) }\end{array}$ & $t_{i}$ & current time $(\mathrm{s})$ \\
\hline$h_{m}^{(k)}$ & $\begin{array}{l}\text { maximum undeformed chip thickness of } \\
\text { grain } k(\mathrm{~m})\end{array}$ & $\Delta t$ & time increment (s) \\
\hline$h_{\max }$ & $\begin{array}{l}\text { maximum undeformed chip thickness for all } \\
\text { the grains }(m)\end{array}$ & $t_{0}$ & start time of heat source movement (s) \\
\hline $\begin{array}{l}h_{\text {ploughing, }}^{(k)} \text { cutting } \\
\quad\end{array}$ & $\begin{array}{l}\text { critical penetration depth for grain } k \text { to start } \\
\text { ploughing and cutting (or chip formation } \\
\text { stage) }(m)\end{array}$ & $U_{\text {total }}$ & total specific grinding energy $\left(\mathrm{J} \cdot \mathrm{m}^{-3}\right)$ \\
\hline$k_{g, w}$ & $\begin{array}{l}\text { thermal conductivity of abrasive material and } \\
\text { of workpiece material }\left(\mathrm{W} \cdot \mathrm{m}^{-1} \cdot \mathrm{K}^{-1}\right)\end{array}$ & $U_{\text {stages }}$ & $\begin{array}{l}\text { specific grinding energy generated during } \\
\text { the rubbing, ploughing and cutting stage } \\
\text { when stages are rubbing, ploughing and } \\
\text { cutting }\left(\mathrm{J} \cdot \mathrm{m}^{-3}\right)\end{array}$ \\
\hline$L_{\text {cube }}$ & side length of the unit cube (m) (see Fig.5) & $V_{\text {wheel }}$ & grinding wheel volume $\left(\mathrm{m}^{3}\right)$ \\
\hline$l_{c, g}$ & $\begin{array}{l}\text { realistic and geometrical wheel-workpiece } \\
\text { contact length }(\mathrm{m})\end{array}$ & $v_{s, w}$ & $\begin{array}{l}\text { grinding wheel and workpiece feed speed } \\
\left(\mathrm{m} \cdot \mathrm{s}^{-1}\right)\end{array}$ \\
\hline$M, N$ & $\begin{array}{l}\text { abrasive size and structure number of a } \\
\text { grinding wheel (\#) }\end{array}$ & $\left(v_{s x}, v_{s y}, v_{s z}\right)$ & $\begin{array}{l}\text { velocities of a heat source movement } \\
\text { separately along the } \mathrm{X}, \mathrm{Y}, \mathrm{Z} \text { axes }\left(\mathrm{m} \cdot \mathrm{s}^{-1}\right)\end{array}$ \\
\hline$m$ & $\begin{array}{l}\text { total number of the moving heat sources } \\
\text { (cutting grains) in the computational domain }\end{array}$ & $(x, y, z)$ & genetic position (m) \\
\hline$n_{g}$ & total grain number in a grinding wheel & $\left(x^{\prime}, y^{\prime}, z^{\prime}\right)$ & heat source position $(\mathrm{m})$ \\
\hline$Q$ & $\begin{array}{l}\text { heat energy provided by an instantaneous } \\
\text { heat source }(\mathrm{J})\end{array}$ & $\left(x_{c}, y_{c}, z_{c}\right)$ & $\begin{array}{l}\text { center coordinate of the unit cube }(\mathrm{m}) \text { (see } \\
\text { Fig.5) }\end{array}$ \\
\hline$q(x)$ & $\begin{array}{l}\text { heat flux distribution along the contact length } \\
x\left(\mathrm{~W} \cdot \mathrm{m}^{-2}\right)(\text { see Fig. } 1)\end{array}$ & $\left(x_{g}^{(k)}, y_{g}^{(k)}, z_{g}^{(k)}\right)$ & grain $k$ location $(\mathrm{m})$ \\
\hline $\bar{q}$ & $\begin{array}{l}\text { average heat flux of the moving heat source } \\
\left(\mathrm{W} \cdot \mathrm{m}^{-2}\right)\end{array}$ & $\left(x_{\text {ran }}, y_{\text {ran }}, z_{\text {ran }}\right)$ & $3 \mathrm{D}$ random vector $(\mathrm{m})$ (see Fig.5) \\
\hline$q_{\text {chip,cool }}$ & $\begin{array}{l}\text { heat flux taken away by chips and convective } \\
\text { coolants }\left(\mathrm{W} \cdot \mathrm{m}^{-2}\right)\end{array}$ & $\alpha$ & $\begin{array}{l}\text { thermal diffusivity of workpiece material } \\
\left(\mathrm{m}^{2} \cdot \mathrm{s}^{-1}\right)\end{array}$ \\
\hline$q_{\text {total }}$ & $\begin{array}{l}\text { total heat flux flowing into grinding zone } \\
\left(\mathrm{W} \cdot \mathrm{m}^{-2}\right)\end{array}$ & $\zeta$ & $\begin{array}{l}\text { random variable conforming normal } \\
\text { distribution }(\mathrm{m})\end{array}$ \\
\hline$q_{s, w c, w c s}$ & $\begin{array}{l}\text { heat flux flowing into grinding wheel, } \\
\text { workpiece and wheel-workpiece system } \\
\left(\mathrm{W} \cdot \mathrm{m}^{-2}\right)\end{array}$ & $\lambda_{s, w}$ & $\begin{array}{l}\text { Poisson's ratio of a wheel and workpiece } \\
\text { material }\end{array}$ \\
\hline$q_{w}$ & heat flux left in workpiece $\left(\mathrm{W} \cdot \mathrm{m}^{-2}\right)$ & $\tau, \rho$ & $\begin{array}{l}\text { shear stress }\left(\mathrm{N} \cdot \mathrm{m}^{-2}\right) \text { and mass density of } \\
\text { workpiece material }\left(\mathrm{kg} \cdot \mathrm{m}^{-3}\right)\end{array}$ \\
\hline$q_{t_{i}}^{(k)}$ & $\begin{array}{l}\text { heat flux generated by grain } k \text { at the time } t_{i} \\
\left(\mathrm{~W} \cdot \mathrm{m}^{-2}\right)\end{array}$ & $\varphi$ & grain volume rate of a grinding wheel (\%) \\
\hline$q_{\Delta t}$ & $\begin{array}{l}\text { average flux of a heat source during the time } \\
\text { increment } \Delta t\left(\mathrm{~W} \cdot \mathrm{m}^{-2}\right)\end{array}$ & $\Omega(x, y, z)$ & computational domain $(\mathrm{m})$ \\
\hline
\end{tabular}

note: SGDTM refers to stochastically grain-discretised temperature model that proposed in this study

\section{Introduction}

Grinding process could be considered as a high-efficiency and low-cost finishing operation. However, grinding specific energy (referring to the required energy to remove per unit volume of material) is relatively high [1] and most of the energy is converted into heat [2]. The excessive heating might lead to the unwanted tempering, rehardening, or burning of the workpiece and further degrade both the metallurgical characteristics and mechanical properties of the workpiece (e.g. microstructure phase transformation, fatigue strength, micro-hardness and residual stresses) [3]. To this end, many analytical, numerical and experimental efforts on the modeling, prediction and measurement of grinding heat/temperature have been performed.

In analytical studies, various thermal models have been developed to predict workpiece temperature so as to understand grinding heat and to avoid thermal damage. Hahn [4] claimed that most grinding heat was generated by abrasive grain-workpiece rubbing thus he considered the wheel-workpiece 
contact area as a heat source with the horizontal uniform distributed heat flux (denoted as $q(x)$ ) within the grinding zone moving upon an adiabatic surface at the workpiece feed speed $v_{w}$ (see Fig. 1a) [5, 6]. This heat flux was employed in Ref. [7] for simplicity and was reported to be adequate to predict thermal damage, although the realistic flux distribution was experimentally proved more complex [8, 9]. The heat source with the horizontal linear increasing heat flux was also proposed [10-15] (see Fig.1b), to emulate the grinding-induced heat that could be considered approximately proportional to undeformed chip thicknesses [16], i.e. the heat flux at the trailing edge of the contact zone was assumed to be more intense than that at the leading edge. The comparison of the above two flux distributions showed that $[10,11]$, the maximum temperature predicted by both of the distributions was quite similar while the calculated temperature distributions showed only small differences in shapes at the beginning of the wheel-workpiece contact. For the high efficiency deep grinding (HEDG), Rowe and Jin assumed the wheel-workpiece contacts as the moving heat sources with the oblique linear increasing [17] (Fig.1c) and horizontal circular [12, 18] (Fig.1d) heat fluxes, because in the HEDG, the depth of cut reached the values as high as $10 \mathrm{~mm}$ [19] and cannot be ignored as in the shallow grinding thus, the wheel-workpiece contact zone could not be assume to be horizontal any more. More detailed analysis was given in Ref. [20] where theoretical derivation proved that, it is possible to reduce specific energy and achieve remarkably high material removal rates with low temperatures using high wheel and workpiece speeds. Jin and Cai [21] also proposed an oblique heat source model but with the uniformly-distributed heat flux (Fig.1e). In comparison with others, Jin and Cai's model (Fig.1e) was reported to be more accurate for the creep-feed grinding, while Rowe's oblique heat source with triangle heat flux [17] (Fig.1c) could more accurately predict ground surface temperature during the HEDG.

Apart from these aspects, heat partition also have been researched, which refers to the percentages of total thermal energy that flows into cutting fluids, chips, the wheel (or abrasive grains), and the workpiece. DesRuisseaux and Zerkle [22] described the convective cooling effects of cutting fluids by using a uniformly-distributed convective heat flux $q_{\text {cool }}$ over the entire workpiece surface (Fig.1f). Rowe [1] experimentally measured the $q_{\text {cool }}$ values in the shallow grinding experiments (when $v_{s}$ of $30 \mathrm{~m} / \mathrm{s}, v_{w}$ of $0.2 \mathrm{~m} / \mathrm{s}$ and $a_{p}$ of $10 \mu \mathrm{m}$ ), which were $13.5 \mathrm{~W} / \mathrm{mm}^{2}$ for the water-based and 7.7 $\mathrm{W} / \mathrm{mm}^{2}$ for the oil-based cutting fluids. Malkin and Cook [23] claimed that chips would not be melt before being detached in grinding thus the heat energy that flows into chips would be limited by the chip melting energy, which was experimentally found to be $6 \mathrm{~J} / \mathrm{mm}^{3}$ for ferrous materials. Guo and Malkin [24] presented the transient thermal analysis to predict the burn-out heat flux based on the critical temperature of the cutting fluid boiling. The micro-scale thermal model was also suggested by Hou et al. [25], where statistical distribution of the abrasive grains on the wheel surface was considered, and experiments proved the accuracy and advance of the model.

The numerical studies on grinding heat have been conducted mainly by using the finite element method (FEM) owing to its strong capabilities not only to simulate the elastoplastic material behaviors (e.g. chip formation) but also to perform the multi-physics coupling analysis (e.g. thermoelastoplastic).

Mahdi and Zhang [26] performed 2D FEM simulation of grinding temperature, in which the heat source was depicted by a linear increasing heat flux and the thermal properties of the steel EN23 were programmed to be temperature-dependent. Biermann and Schneider [27] conducted similar simulations but using the heat source with the uniformly-distributed heat flux and taking the consideration of the convective cooling of the cutting fluids. Moulik et al. [28] obtained the transient 
thermal stresses and temperatures by FEM simulations, in which thermal elastoplastic finite elements were used. More powerful FEM model was developed by Hamdi et al. [29], which enables the prediction of grinding-induced residual stresses and austenitic transformations of AISI 52100.

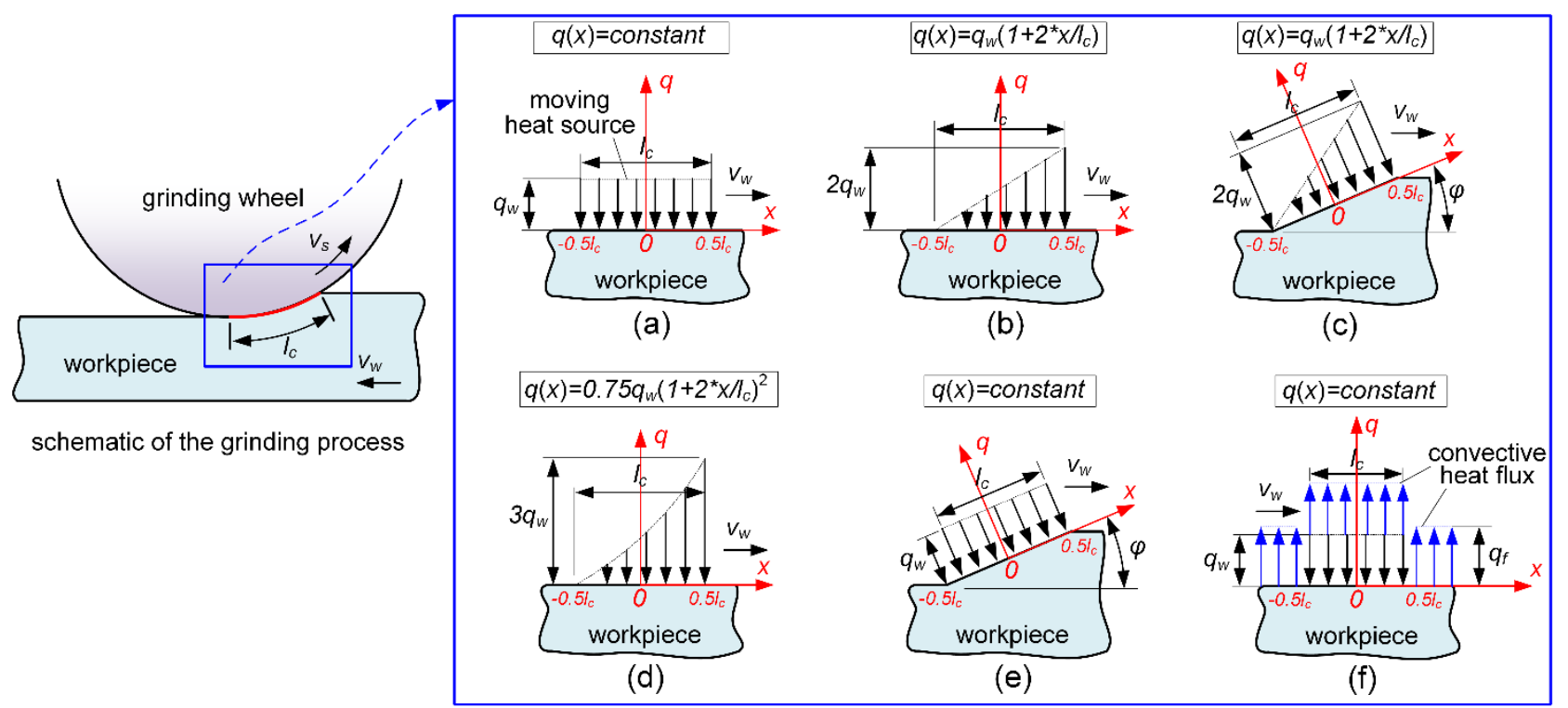

Fig.1 Schematic of grinding heat based on the moving heat source (the heat flux is denoted as $q(x)$ ) with (a) horizontal uniform distributed [4-6] (b) horizontal linear increasing [10-12] (c) oblique linear increasing [17] (d) horizontal circular [12] (e) oblique uniform distributed [21] and (f) horizontal uniform distributed and convective cooling heat fluxes [22]

In order to validate the analytical and numerical studies, various experimental efforts also have been made to measure grinding heat/temperature.

The studies including Refs.[14, 27, 29-33] embedded standard two-pole thermocouples beneath the ground surface of the split workpiece and measured grinding temperature at different distances from the ground surface. This technique could obtain good-quality thermovoltage signals owing to the good insulation and the stable measure junction [1, 34], but as thermocouples are not positioned actually on the ground surface but beneath the surface, surface temperature was usually obtained by performing mathematical extrapolation. because the temperature gradient near the surface would be steep and non-linear, the measure accuracy was considered to be largely unstable [9]. Except for the standard thermocouples, single-pole thermocouples were also suggested in some researches $[17,18,35,36]$, for which one pole of the thermocouples was usually a constantan wire and housed in the split workpiece while the other pole was the workpiece ifself. During the grinding process, the grinding wheel would smear the constantan wire onto the workpiece material thus, the measure junction could be formed upon the ground surface. Besides, thin film thermocouples or foil thermocouples were also utilised in Refs.[2, 37-41], which have the advantages including the extremely small size of the measure junction to capture temperature signals within a very small area [42].

Apart from the heat conduction based measurement methods mentioned above, the heat radiation based techniques also have been proposed recently. Ueda et al. [43-45] used an infrared radiation pyrometer and optical fibers to measure the single grain temperature, even right after the grain passed the ground surface. By using an improved system equipped with a two-color pyrometer with a fused fiber coupler [46], grain-workpiece interface temperature was measured. Rapid temperature rise was observed after a very short time of around $0.1 \mathrm{~ms}$. Hwang et al. [47] and Mohamed et al. [48] obtained the temperature on the side surface of the ground workpiece by using an infrared 
imaging system allowing temperature profile with high spatial and temporal resolution to be obtained. The thermography technique was also employed [49-51] to obtain the grinding temperature distribution, based on which inverse methods could be used to obtain more realistic heat flux values and distributions of the heat source.

Although many efforts have been made in the above studies, there is still a gap in understandings of grinding temperature/heat as a dependence on process stochasticity. For analytical and numerical studies, most efforts have been made based on the assumption that the wheel-workpice contact area could be considered as a moving band heat source, while in reality this is the result of a large amount of discrete interactions between stochastically distributed grains and workpiece and therefore, the heat within the contact area should be discontinuous and non-uniform both along the feed and wheel width directions [1]. For experimental studies, up to now the thermocouple-based techniques have mainly been used to provide 1D macro-scale temperature data (i.e. temperature curve of a certain point beneath the ground surface vs. time) and no 2D/3D temperature maps with micro-scale (or grain-scale) details could be obtained, largely limiting deep understandings, while utilisation of heat-radiation-based measurement techniques have significant difficulties to observe the wheel-workpiece contact area from any angle when the wheel and workpiece are in contact.

To address the research gaps mentioned above, this paper proposes a stochastically graindiscretised temperature model (SGDTM) to obtain 2D/3D grinding temperature maps by individually calculating the heat generated by each grain based on the determination of each grain-workpiece micro-interaction and then superimposing it. The contributions of this paper might include:

The theoretical derivation of 2D/3D grinding zone temperature with micro-scale details based on the determination of different grain-workpiece micro-interaction regimes (i.e. rubbing, ploughing and cutting);

The availability of the full 2D/3D grinding temperature maps of the wheel-workpiece contact area with detailed thermal information at the grain scale, proving that assumption made in most previous studies might be not accurate enough to depict realistic grinding zone temperature, because the heat fluxes are proved to be neither uniformly-distributed along the wheel width direction nor continuous along the workpiece feed direction;

O The feasibility of the temperature map measurement technique based on the sacrificial thermocouple array, which could, for the first time, visually present the grinding heat generation process at the grain scale (i.e. containing the thermal impact induced by every single grain) and, more importantly, provide a solid basis for more in-depth understanding of grinding heat than using the common approach depending on single thermocouple.

\section{Problem definition}

Grinding process could be considered as a material removal process where a multitude of discrete grains simultaneously interact with the workpiece. Therefore, it would be reasonable to understand the generated grinding heat as the sum of heat generated by a number of discrete single cutting grains. Given that the size of each grain-workpiece contact area is relatively small in comparison with the size of the whole wheel-workpiece contact area [52], each grain-workpiece contact could probably be treated as the point heat source and therefore grinding heat can be analyzed based on the moving point heat source theory [53]. 
Although it has been already successfully utilised in the heat calculation for some manufacturing processes like welding [54] and laser machining [55], the application of the moving heat source theory in the grinding process however has several particularities:

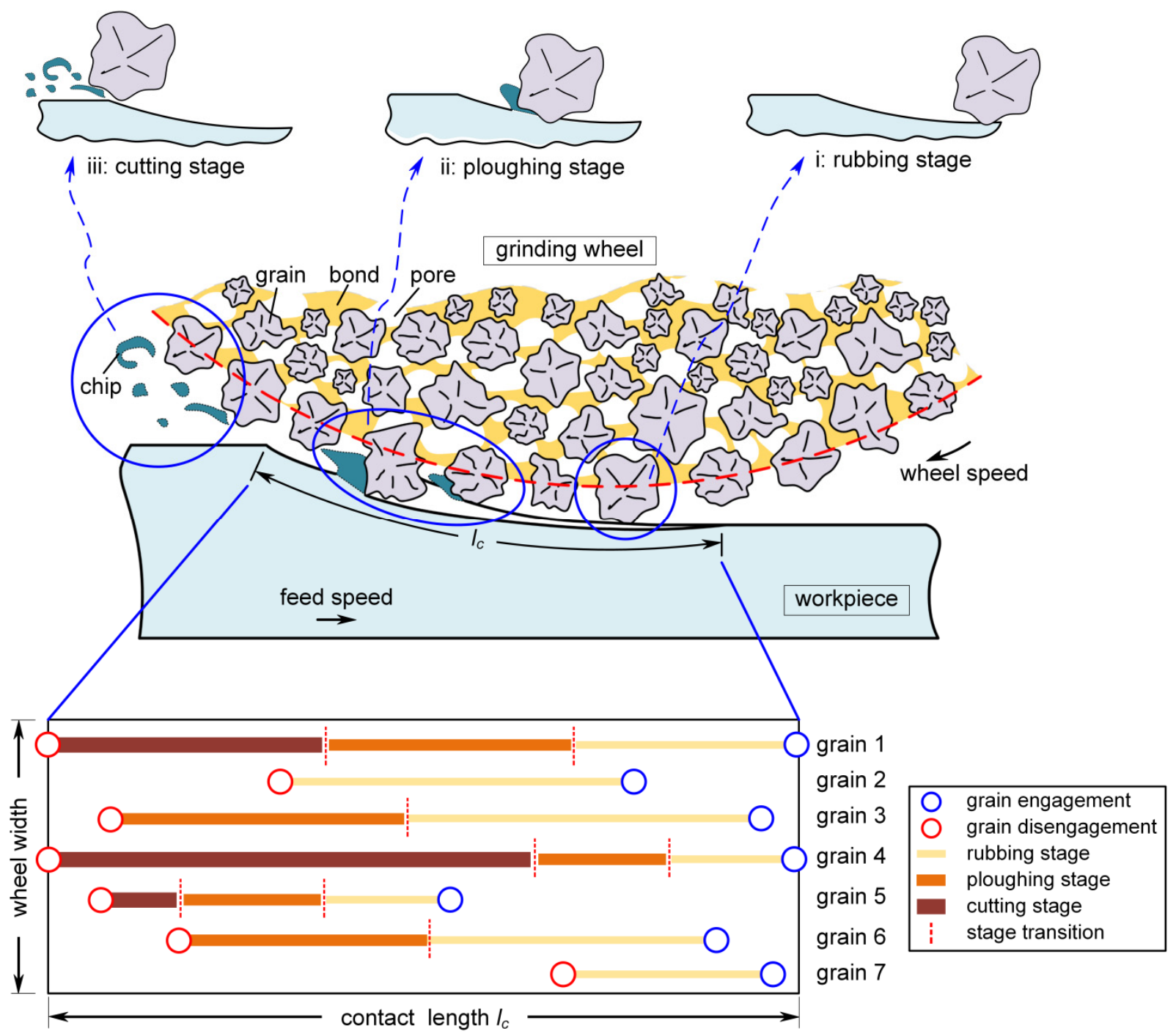

Fig.2 Schematics of the grinding process where grains are in different sizes and randomly distributed on the wheel surface and the varied grain engagement, disengagement, and stage transition points for the grains with different protrusion heights

Onlike other machining techniques, a multitude of cutting grains are simultaneously involves in grinding process, thus the number of moving heat sources that simultaneously interact with the workpiece should be large. Moreover, because the grains are randomly-distributed on the grinding wheel surface (see middle diagram in Fig.2), these heat sources generated by individual grains should, therefore, be modeled based on the stochasticity of the wheel topography.

It is believed [9] that there are three possible stages of the grain-workpiece interaction regimes (see top diagram in Fig.2): (i) the rubbing stage where elastic and plastic deformations of workpiece materials take place, (ii) the ploughing stage where scratch marks appear and ridges are formed as materials are pushed to the sides of scratches, and (iii) the cutting stage where chips are produced and materials are removed.

However, different grain sizes and their random locations on the wheel periphery would lead to various grain protrusion heights; therefore, the engagement, disengagement and regime 
transition points of each individual grain would be different [1,9]. Some grains might not experience all the three possible stages (see the grain 2,3,6,7 in bottom diagram in Fig.2).

Experiments in Ref. [56] indicated that, different regimes of grain-workpiece interactions also result in different levels of heat generation rates. Therefore the heat flux of each single moving heat source (or cutting grain) should be time-dependent based on the grain-workpiece contact regimes. Moreover, even for the grains which are experiencing the same contact regime, the generated grinding heat would be also different, depending on current penetration depths of each grain.

All the above factors, including the (i) random wheel topography, (ii) determination strategy of grainworkpiece contact regimes, and (iii) heat calculation based on time-dependent grain penetration depths, have been rarely considered in the previous studies, and are attempted to be solved in this study.

\section{Model description}

The basic idea of the proposed SGDTM is to calculate local temperature field induced by the heat generated by each grain according to the moving point heat source theory [5] and then superimpose each local field to obtain the whole temperature domain for every grinding moment. During the moving point heat modeling, the only unknown parameter would be the heat flux flowing into each grain (explained in Section 3.1), which could be obtained by: (i) calculation of heat flux flowing into the workpiece $q_{w}$ (explained in Section 3.2) and (ii) partition of $q_{w}$ into each cutting grain (explained in Section 3.3) based on the determination of grain-workpiece contact regimes (explained in Section 3.4).

\subsection{Basics of grinding temperature calculation}

Based on the energy conservation law, Jaeger [5] derived the 3D temperature domain of the homogenous and isotropic material induced by an instantaneous point heat source as follows:

$$
T\left(x, y, z, t_{i}\right)=T_{0}+\frac{2 Q}{C_{p} \rho\left(4 \pi \alpha t_{i}\right)^{3 / 2}} \exp \left[-\frac{(x-x)^{2}+(y-y \prime)^{2}+\left(z-z^{\prime}\right)^{2}}{4 \alpha t_{i}}\right]
$$

where

$$
\left.T\left(x, y, z, t_{i}\right)\right|_{t_{i}=0}=T_{0} \text { and } \frac{\partial T}{\partial x}=\frac{\partial T}{\partial y}=\frac{\partial T}{\partial z}=0 \text { for } x, y, z \rightarrow \pm \infty
$$

Based on this, Carslaw and Jaeger [53] further obtained the temperature domain induced by a moving heat source as Eq.(3).

$$
T\left(x, y, z, t_{i}\right)=\int_{0}^{t_{i}} T_{0}+\frac{2 Q}{c_{p} \rho\left(4 \pi \alpha t_{i}\right)^{3 / 2}} \exp \left[-\frac{(x-x \prime)^{2}+(y-y \prime)^{2}+(z-z \prime)^{2}}{4 \alpha t_{i}}\right] d t_{i}
$$

Given that the average heat flux of each moving heat source (i.e. cutting grain) in grinding $\bar{q}$ is varied at any grinding moment depending on cutting grain numbers and grain penetration depths, the continuous path of each single grain in grinding is discretised by performing the discrete integration of Eq.(3) so that the grain-workpiece interaction regimes could be achievable, i.e. the 3D 
temperature domain induced by an moving infinitesimal small heat source could be obtained by:

$$
T\left(x, y, z, t_{i}\right)=\sum_{j=n}^{\left(t_{i}-t_{0}\right) / \Delta t} \frac{2 q_{t_{i}-t_{0}-j \Delta t} \Delta t}{C_{p} \rho\left[4 \pi \alpha\left(t_{i}-t_{0}-j \Delta t\right)\right]^{3 / 2}} e^{\left[-\frac{\left(x-x^{\prime}-j \Delta t v_{S x}\right)^{2}+\left(y-y^{\prime}-j \Delta t v_{y x}\right)^{2}+\left(z-z \prime-j \Delta t v_{S Z}\right)^{2}}{4 \alpha\left(t_{i}-t_{0}-j \Delta t\right)}\right]},
$$

where $n$ refers to the total number of active grains interacting with workpiece. By further discretely integrating Eq.(4) with respect to heat sources, the full 3D temperature domain in wheel-workpiece contact area can be expressed as:

$$
T\left(x, y, z, t_{i}\right)=\sum_{k=1}^{m} \sum_{j(k)=n}^{\left(t_{i}-t_{k}^{(k)}\right) / \Delta t} \frac{2 q_{t_{i}-t_{0}-j \Delta t^{-}-\Delta t}^{(k)}}{c_{p} \rho\left[4 \pi \alpha\left(t_{i}-t_{0}^{(k)}-j^{(k)} \Delta t\right)\right]^{3 / 2}} e^{-\frac{\left(x-x^{\prime}-j(k) \Delta t v_{s x}\right)^{2}+\left(y-y^{\prime}-j(k) \Delta t v_{y x}\right)^{2}+\left(z-z I^{\prime}-j(k) \Delta t v_{S z}\right)^{2}}{4 \alpha\left(t_{i}-t_{0}-j \Delta t\right)}},
$$

where the superscript $(k)$ indicates any point heat source and $j$ is the total number of time steps.

Eq.(5) therefore is employed as the main calculation principle for the temperature field induced by a single cutting grain. It could be observed that $q_{t_{i}-t_{0}-j \Delta t}^{(k)}$ (the heat flux induced by the grain $k$ at the moment $t_{i}-t_{0}-j \Delta t$ ) is the only unknown variable in Eq.(5) if the workpiece material properties, machining parameters and information of grain-workpiece contacts are given. The following two sections therefore are focused on the determination of $q_{t_{i}-t_{0}-j \Delta t}^{(k)}$ by: (i) the calculation of the total heat flux generated into the workpiece $q_{w}$ (Section 3.2) and (ii) the partition of $q_{w}$ into each grain based on the determination of the grain-workpiece contact regimes (Section 3.3).

\subsection{Heat flux left in the workpiece $q_{w}$}

It could assume that all the input grinding energy is dissipated by the grain-workpiece interactions and is finally converted into thermal energy within the grinding zone [1], i.e. the total heat flux flowing into the grinding zone $q_{\text {total }}$ can be expressed as:

$$
q_{\text {total }}=\frac{F_{t} \cdot v_{s}}{b \cdot l_{c}}=\frac{F_{t^{\prime} \cdot v_{S}}}{l_{c}}
$$

where the realistic wheel-workpiece contact length $l_{c}$ could be calculated according to Ref. [57].

Given that the amount of the coolants that can be transported into the grinding zone is very limited [9], the total heat flux $q_{\text {total }}$ is assumed to flow into two parts: (i) the chips $q_{\text {chip }}$ and (ii) the wheelworkpiece system $q_{w c s}[1,2,9]$ (see Fig.3), where $q_{c h i p}$ was proved to be close to the melting energy of the chips and can be calculated by $q_{c h i p}=\rho_{w} \cdot c_{w} \cdot T_{m p} / l_{c}$ [9].

The heat flux $q_{w c s}$ also would be dissipated into two heat sinks [1, 2, 9]: (i) the one represented by the workpiece $q_{w c}$ and (ii) the another one represented by the wheel $q_{s}$, where the relation between $q_{w c}$ and $q_{s}$ was given in Ref. [58]. Also, some of the thermal energy in $q_{w c}$ would be taken away by the coolants, while only the left energy $q_{w}$ has the thermal effects on the increase of the workpiece temperature rise. Given the above analysis, $q_{w}$ could be finally expressed as:

$$
q_{w}=\frac{d_{s}^{-0.5}\left(F_{t}^{\prime} \cdot v_{s}-\rho_{w} c_{w} T_{m p}\right)}{\sqrt{a_{p}+200 F_{n}^{\prime}\left(\frac{1-\lambda_{S}^{2}}{\pi E_{s}}+\frac{1-\lambda_{w}^{2}}{\pi E_{w}}\right)}}\left(1+\frac{0.974 k_{g}}{\left(1-e^{-\tau / 1.2}\right) \sqrt{k_{w} c_{w} \rho_{m p} r_{e} v_{s}}}\right)-h_{c o o l}\left(T_{c e}-T_{c s}\right) .
$$




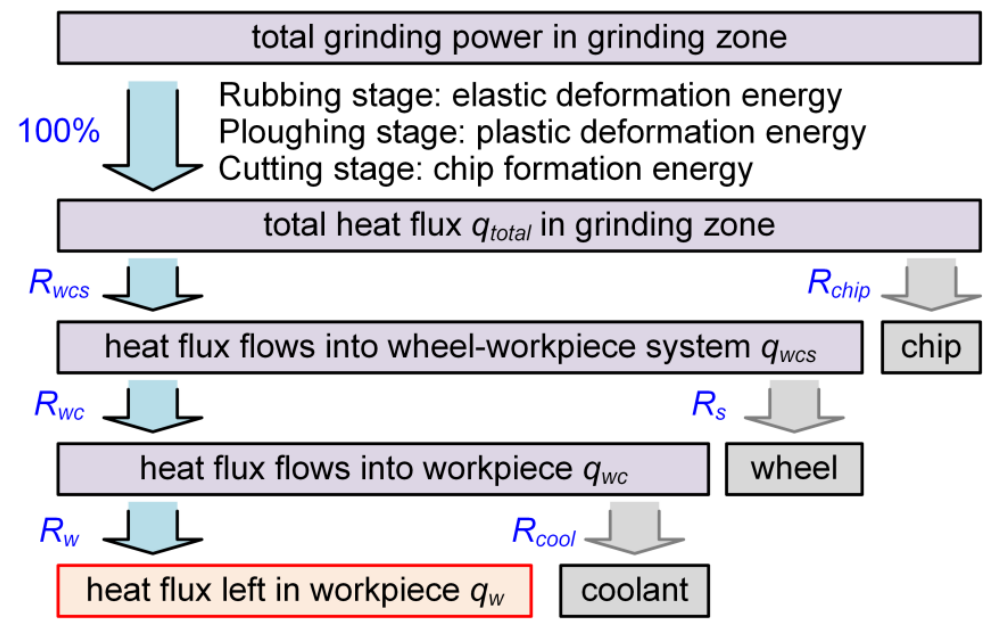

Fig. 3 Schematics of the heat fluxes in the grinding process based on Refs. $[1,2,9]$

\subsection{Partition of the heat flux $q_{w}$ into each grain based on different stages of grain-workpiece contacts}

Single-grit grinding experiments proved that $[56,59]$, if it assumes the grains experience all three possible grain-workpiece contact stages, the specific grinding energy can be considered as the sum of these three components with different weighting coefficients corresponding to contact stages, i.e.

$$
U_{\text {total }}=0.5\left(U_{\text {ploughing }}+U_{\text {cutting }}\right)+U_{\text {rubbing }} .
$$

It therefore would be reasonable to assume the heat flux generated in rubbing, ploughing and cutting regimes also follows the weight coefficients in Eq.(8), i.e.

$$
q_{w}=0.5\left(q_{\text {ploughing }}+q_{\text {cutting }}\right)+q_{\text {rubbing }} .
$$

Given that the heat generated by a single abrasive grain is linearly dependent to the chip volume $[56,59]$ and the chip volume could be regarded as the integration of the continuously-changing cross-sections of the chips along their contact length (see Fig.4), it therefore assume the heat generated by a single grain per unit time (i.e. the heat flux $\left.q_{t_{i}}^{(k)}\right)$ is proportional to the volume of the removed material per unit time (or the grain penetration $S_{g p_{-} t_{i}}^{(k)}$ in Fig.4), i.e.

$$
q_{t_{i}}^{(k)} \propto S_{g p_{-} t_{i}}^{(k)}
$$

where $S_{g p_{-} t_{i}}^{(k)}$ could be calculated by

$$
S_{g p_{-} t_{i}}^{(k)}=0.5\left[d_{g}^{(k)}\right]^{2} \arccos \left[1-\frac{2 h_{g p_{-} t_{i}}^{(k)}}{d_{g}^{(k)}}\right]-\left(0.5 d_{g}^{(k)}-h_{g p_{-} t_{i}}^{(k)}\right) \sqrt{h_{g p_{-} t_{i}}^{(k)}\left(d_{g}^{(k)}-h_{g p_{-} t_{i}}^{(k)}\right)} .
$$



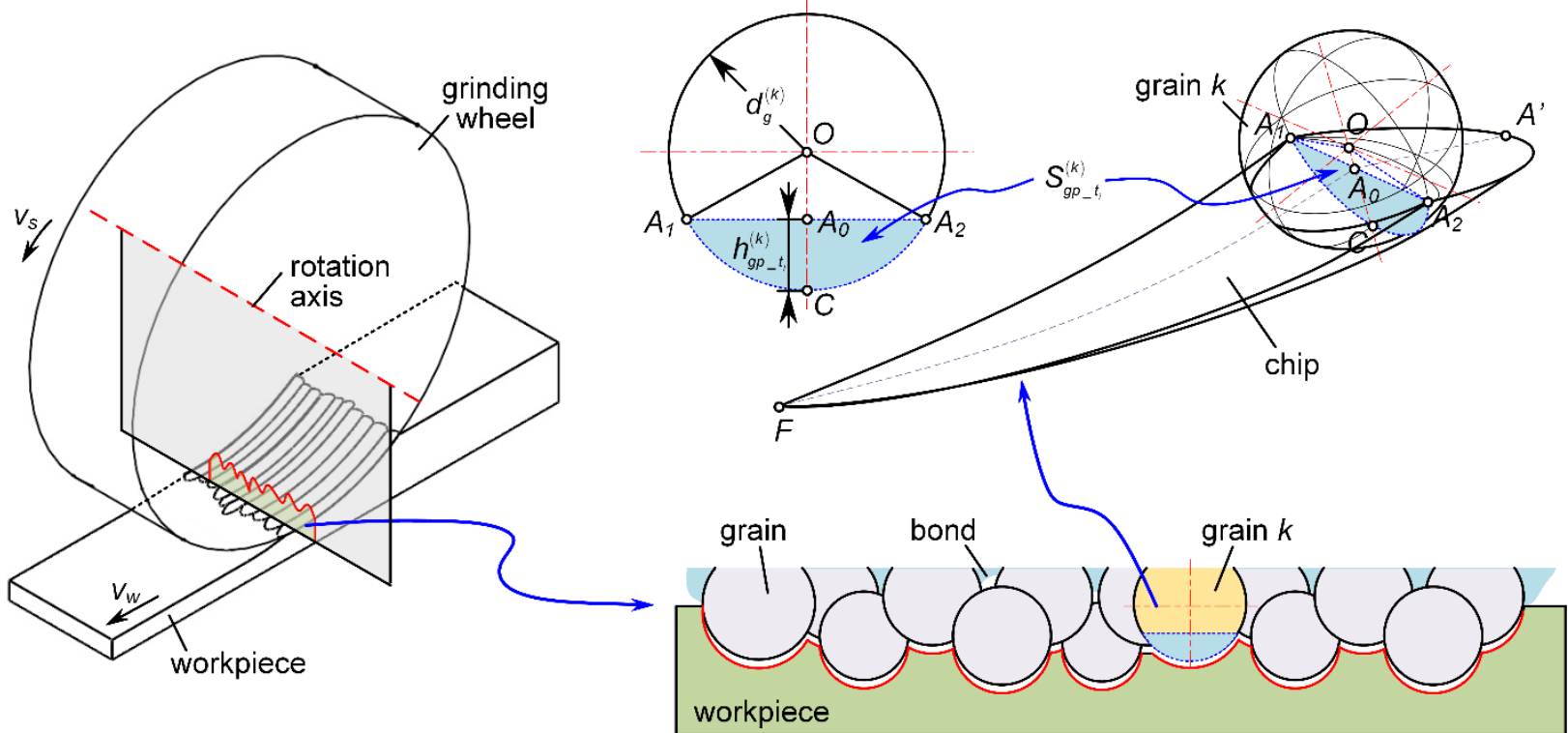

Fig.4 Schematics of the grain penetration area and chip formation in the grinding process

Based on Eqs.(9)-(11), it could be obtained that

$$
\begin{aligned}
& q_{\text {rubbing }}=q_{w} \cdot \frac{s_{g p_{-} t_{i}}^{\text {rubbing }}}{s_{g p_{-} t_{i}}^{\text {rubbing }}+0.5\left(S_{g p_{-} t_{i}}^{\text {ploughing }}+s_{g p_{-} t_{i}}^{\text {cutting }}\right)}, \\
& q_{\text {ploughing }}=q_{w} \cdot \frac{0.5 \cdot S_{g p_{-} t_{i}}^{\text {ploughing }}}{S_{g p_{-} t_{i}}^{\text {rubbing }}+0.5\left(S_{g p_{-} t_{i}}^{\text {lloughing }_{i}}+S_{g p_{-} t_{i}}^{\text {cutting }}\right)}, \\
& q_{\text {rubbing }}=q_{w} \cdot \frac{0.5 \cdot S_{g p_{-} t_{i}}^{\text {cutting }}}{S_{g p_{-} t_{i}}^{\text {rubbing }}+0.5\left(S_{g p_{-} t_{i}}^{\text {ploughing }}+S_{g p_{-} t_{i}}^{\text {cutting }}\right)} .
\end{aligned}
$$

Therefore the heat flux distributed into each grain at the time $t_{i}$ could be obtained by (i) the determination of which stage the grain $k$ is currently experiencing, and (ii) the calculation based on Eqs.(12)-(15).

\subsection{Determination of the regimes of grain-workpiece interactions}

\subsubsection{Modeling of grinding wheel topography}

The determination of grain-workpiece contact statuses starts with the modeling of random grinding wheel topography. According to Ref. [60], the random grain diameter $d_{g}$ in a certain wheel could be expressed as:

$$
d_{g}=0.5\left(d_{\text {gmax }}+d_{\text {gmin }}\right)+\zeta
$$

where $\zeta$ is a random variable in the range of $\left[-\left(d_{\text {gmax }}-d_{\text {gmin }}\right) / 2,\left(d_{\text {gmax }}-d_{\text {gmin }}\right) / 2\right], d_{\text {mean }}$ could be calculated by $d_{\text {mean }}=15.2 / M$, and $d_{\text {gmax,gmin }}$ can be obtained according to the relation 
table between mesh size and $d_{\text {gmax,gmin }}$ given in Ref. [60].

The wheel topography modeling procedures are presented in Fig.5, which are similar to those performed in Ref. [61], including: (i) discretizing the outer layer of the wheel (with the layer thickness of $d_{\text {gmax }}$ ) into unit cubes (with the cube side length of $L_{\text {cube }}$ ), (ii) initially locating each grain at the geometrical center of a certain cube $\left(x_{c}, y_{c}, z_{c}\right)$, and (iii) adding a 3D random vector $\left(x_{\text {ran }}, y_{\text {ran }}, z_{\text {ran }}\right)$ to the initial grain location to obtain a random wheel topography where $x_{\text {ran }}, y_{\text {ran }}, z_{\text {ran }}$ are required to be smaller than $0.5 L_{\text {cube }}$ to avoid the grain overlap.

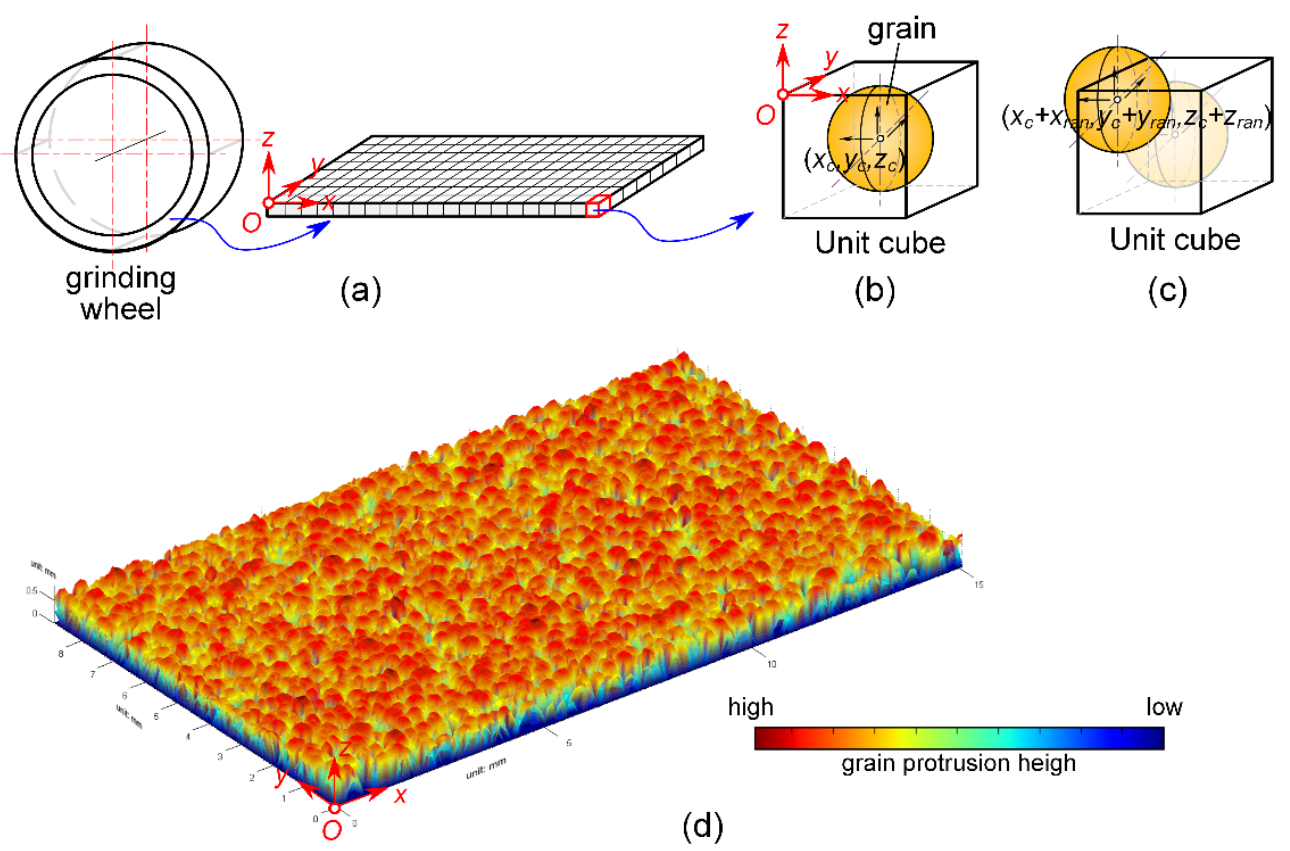

Fig.5 The procedures to model random grinding wheel topography: (a) discretizing the outer layer of the grinding wheel (with the layer depth $d_{\text {gmax }}$ ) into unit cubes (with the cube side length $L_{\text {cube }}$ ), (b) initially locating one grain at the center of a certain cube $\left(x_{c}, y_{c}, z_{c}\right)$, and (c) adding a 3D random vector $\left(x_{r a n}, y_{r a n}, z_{r a n}\right)$ to the initial grain location to obtain a random grinding wheel topography where $x_{\text {ran }}, y_{\text {ran }}, z_{\text {ran }}<0.5 L_{\text {cube }}$ to avoid the grain overlap, and (d) the snapshot of the modeled grinding wheel topography

The total grain number in a certain wheel $n_{g}$ and $L_{c u b e}$ could be obtained based on the grain volume rate $\varphi$, which could be known based on the structure number of the wheel $N$, i.e.,

where

$$
\begin{gathered}
\sum_{k=1}^{n_{g}} \frac{1}{6} \pi\left[d_{g}^{(k)}\right]^{3}<V_{\text {wheel }} \cdot \varphi \& \sum_{k=1}^{n_{g}+1} \frac{1}{6} \pi\left[d_{g}^{(k)}\right]^{3}>V_{\text {wheel }} \cdot \varphi, \\
L_{\text {cube }}=\sqrt[3]{\frac{6 V_{\text {wheel }}}{\pi \cdot n_{g}}},
\end{gathered}
$$

The final wheel topography employed in the following calculation is obtained by recursively running the above procedures until the difference between the modeled and realistic wheel topography measured by the 3D profilometer (Talysurf Hobson Precision, CLI 1000) could be smaller than 10\%. To quantify this difference, three random cross-sections with the sampling length of $0.8 \mathrm{~mm}$ (according to ISO 4287:1998) are extracted from the modeled and realistic topography, and for each cross section profile, the parameters Ra and waviness (according to ISO 4287:1998) are measured and compared as seen in Fig.6. 


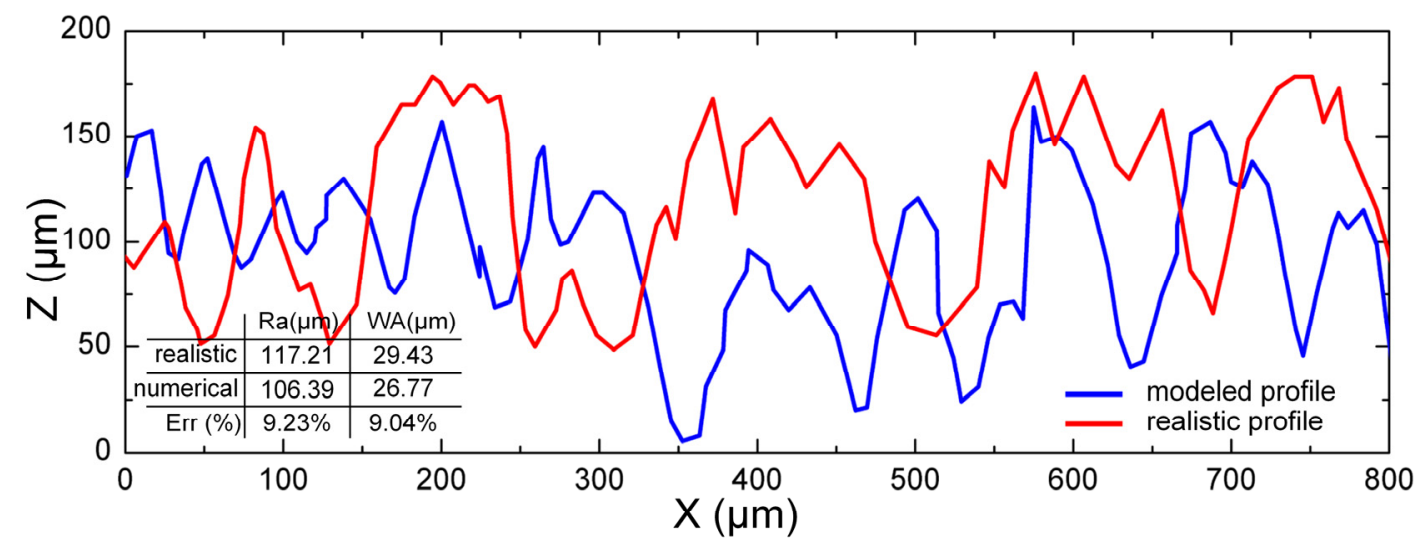

Fig.6 The typical Ra and waviness (according to ISO 4287:1998) comparison result between realistic and modeled wheel topography

\subsubsection{Determination of the stages of grain-workpiece interactions}

It can be seen from the front view of the modeled wheel topography (see Fig.7a) that the maximum undeformed chip thickness for each grain $h_{m}^{(k)}$ would be different and could be expressed as

$$
h_{m}^{(k)}=h_{\max }-\left[d_{g \max }-h^{(k)}\right]
$$

where the maximum undeformed chip thickness for all the grains in a wheel $h_{\operatorname{mmax}}$ could be obtained according to Ref.[9], i.e.

$$
h_{\max }=\left[\frac{6 v_{w}}{\operatorname{crv} v_{s}} \cdot\left(\frac{a_{p}}{d_{s}}\right)^{0.5}\right]^{0.5}
$$

and $h^{(k)}$ is the protrusion height for the grain $k$ and could be obtained by

$$
h^{(k)}=z_{c}^{(k)}+z_{\text {ram }}^{(k)}+0.5 d_{g}^{(k)}
$$

As seen in Fig.7 (b)-(d), the relationship between $h_{m}^{(k)}$ and the critical depths for ploughing and cutting stages $h_{\text {ploughing }}^{(k)}, h_{\text {cutting }}^{(k)}$ determines the total number of regimes that grain $k$ would experience, where according to Ref. [60] $h_{\text {ploughing }}^{(k)}$ and $h_{\text {cutting }}^{(k)}$ could be:

$$
h_{\text {ploughing }}^{(k)}=\delta_{\text {ploughing }} \cdot d_{g}^{(k)}, h_{\text {cutting }}^{(k)}=\delta_{\text {cutting }} \cdot d_{g}^{(k)}
$$

When $h_{m}^{(k)}>h_{\text {cutting }}^{(k)}$, all the possible grain-workpiece contact regimes includes the rubbing, ploughing, and cutting stages (Fig.7b). When $h_{\text {ploughing }}^{(k)}<h_{m}^{(k)}<h_{\text {cutting }}^{(k)}$, the grain would experience only the rubbing and ploughing regimes (Fig.7c) and the parameter $q_{\text {cutting }}$ in Eq.(9) will be 0 . When $h_{m}^{(k)}<h_{\text {ploughing }}^{(k)}$, the only possible stage for the grain $k$ is the rubbing regime (Fig.7d) and the parameters $q_{\text {cutting }}$ and $q_{\text {ploughing }}$ will be 0 .

With respect to which regime the grain $k$ is experiencing at the current time $t_{i}$, it could be easily determined by the relationship between the instantaneous chip thickness at the time $t_{i}$ (denoted as $h_{\text {gp } t_{i}}^{(k)}$ in Fig.4) and $h_{\text {ploughing,cutting }}^{(k)}$. When $h_{\text {gp_ } t_{i}}^{(k)}<h_{\text {ploughing }}^{(k)}, h_{\text {ploughing }}^{(k)}<h_{\text {gp } t_{i}}^{(k)}<h_{\text {cutting }}^{(k)}$ and $h_{\text {gp } t_{i}}^{(k)}>h_{\text {cutting }}^{(k)}$, the grain is separately experiencing the rubbing, ploughing, and cutting stages at time $t_{i}$. 


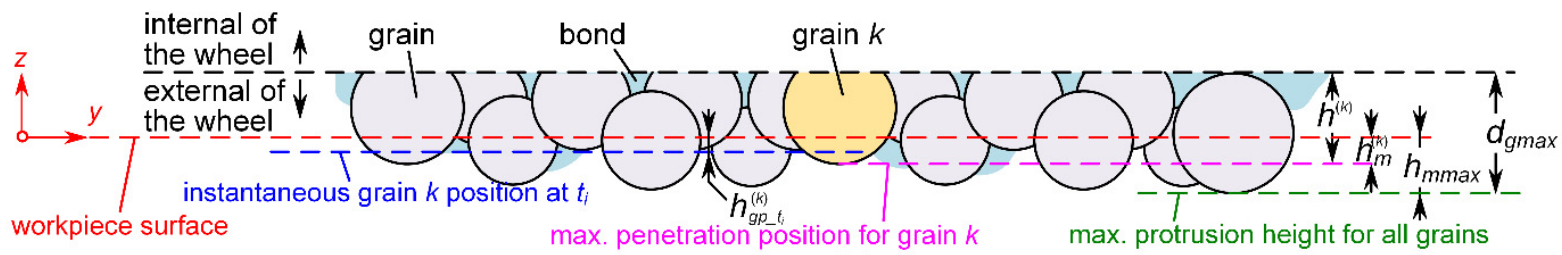

(a)

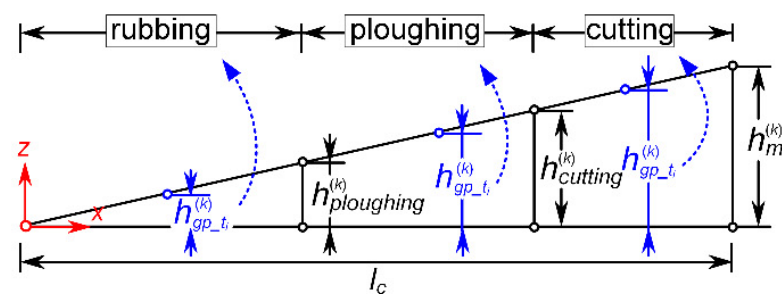

(b)

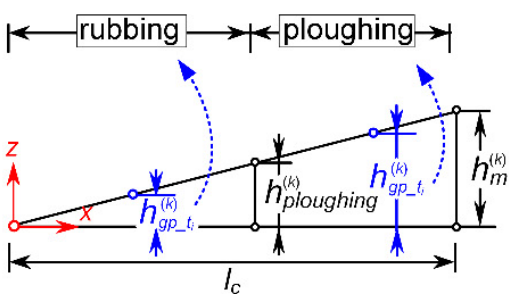

(c)

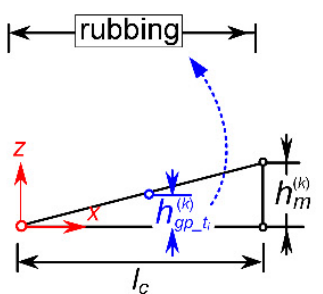

(d)

Fig.7 (a) The front view of the modeled grinding wheel topography, and the possible grain-workpiece contact stages when (b) $h_{m}^{(k)}>h_{\text {cutting }}^{(k)}$, (c) $h_{\text {ploughing }}^{(k)}<h_{m}^{(k)}<h_{\text {cutting }}^{(k)}$ and (d) $h_{m}^{(k)}<h_{\text {ploughing }}^{(k)}$

\subsection{Flowchart}

Based on the above calculations, the calculation strategy of the proposed SGDTM is presented as shown in Fig.8: the total heat flux in the grinding zone $q_{\text {total }}$ is first obtained by Eq.(6) and then the heat flux into the workpiece $q_{w}$ could be gained by Eq.(7). Based on the modeling of grinding wheel topography according to Eqs.(16-19), the grain-workpiece contact stages could be individually determined for each grain based on Eqs.(20-23). Then the partition of $q_{w}$ into each grain could be calculated according to Eqs. $(9,10,12-15)$ and the temperature field induced by the grain $i$ could be achieved by Eq.(4). By summing up the field induced by each individual grain, the final grinding temperature map of the wheel-workpiece contact area could be obtained according to Eq.(5).

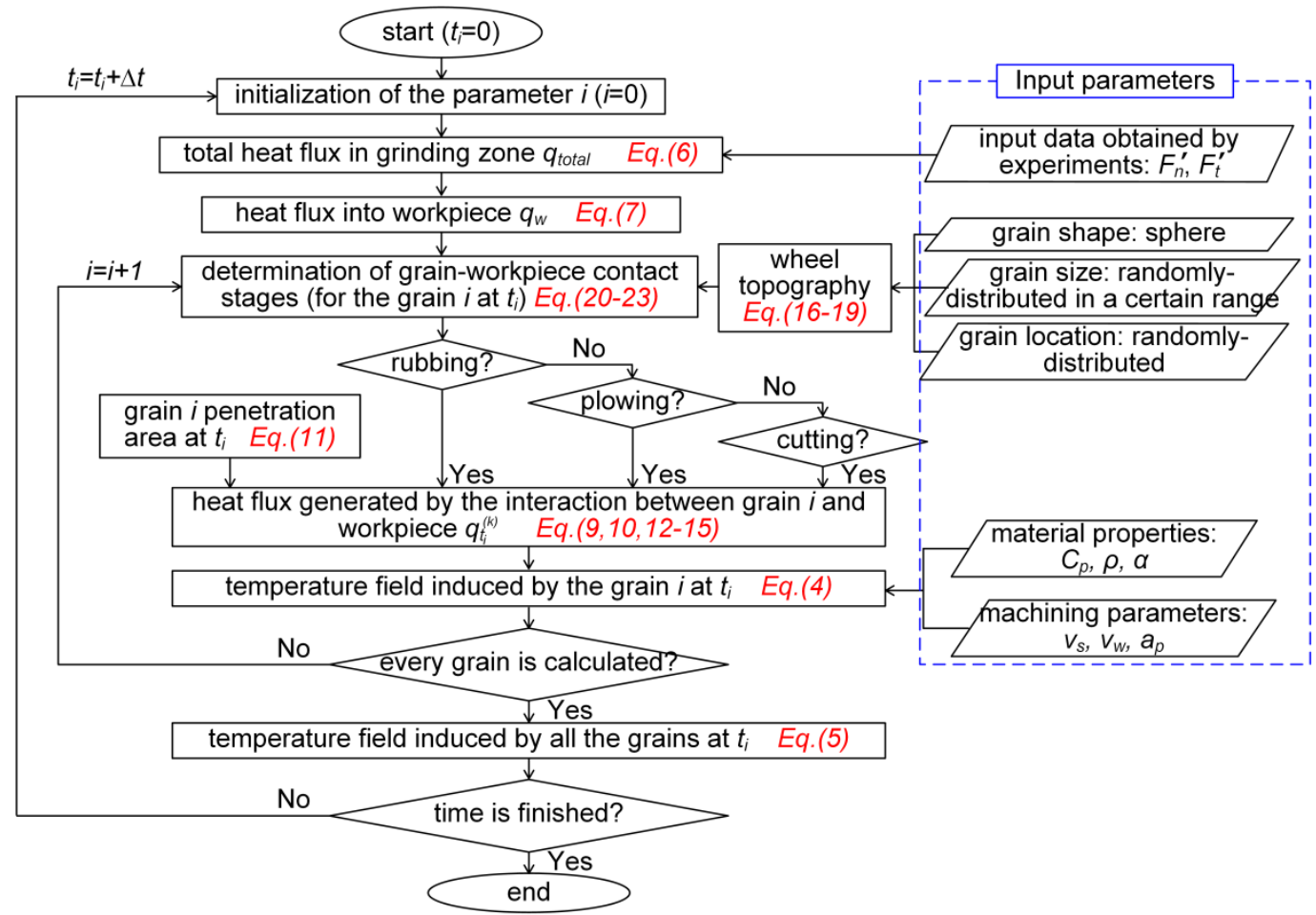

Fig.8 Flowchart of the proposed SGDTM model 


\section{Experimental tests, temperature measurement technique, and methodology for model validation}

To validate SGDTM, a set of experiments utilising a new methodological approach based on an array of sacrificial two pole thermocouples has been proposed to validate the proposed SGDTM.

\subsection{Experiment setup}

Rectangular AISI 1055 (properties in Table 1) testpieces (80 mm $\times 20 \mathrm{~mm} \times 2 \mathrm{~mm}$ ) in combination with a disk-type wheel (WA60L5V) have been employed to perform single-pass down-grinding tests with no cutting fluids. Dressing operations have been performed prior to each trial to ensure similar cutting performances of the wheel by using the dressing wheel MD50N100M1/8 with the dressing ratio -0.6 and dressing depth $15 \mu \mathrm{m}$ (10 times).

Table 1

AISI 1055 properties

\begin{tabular}{cccccccccc}
\hline material & $\rho\left(\mathrm{kg} \cdot \mathrm{m}^{-3}\right)$ & $E_{w}(\mathrm{GPa})$ & $\tau(\mathrm{GPa})$ & $\lambda_{w}$ & $C_{p}\left(\mathrm{~J} \cdot \mathrm{kg}^{-1} \cdot \mathrm{K}^{-1}\right)$ & $k_{w}\left(\mathrm{~W} \cdot \mathrm{m}^{-1} \cdot \mathrm{K}^{-1}\right)$ & $T_{m p}\left({ }^{\circ} \mathrm{C}\right)$ & $\alpha\left(\mathrm{m}^{2} \cdot \mathrm{s}^{-1}\right)$ \\
\hline AISI 1055 & 7840 & 190 & 80 & 0.28 & 477 & 42.6 & 1510 & $3.3 \mathrm{E}-6$ \\
\hline
\end{tabular}

Grinding trials have been performed on the surface grinder (see Fig.9). The dynamometer (Kistler 9257), together with an A/D data acquisition board (National Instruments 6366) has been utilised to capture grinding forces with the sampling rate of $100 \mathrm{kHz}$. Before each trial, the workpiece has been cooled to the ambient temperature $\left(20^{\circ} \mathrm{C}\right)$ to minimise the remanent heat induced by pervious trials.

Given that the depths of cut were experimentally reported to be closely related with grain-workpiece contact regimes and further influenced grinding temperature [9], the wheel and workpiece speeds have been kept constant as $26.9 \mathrm{~m} / \mathrm{s}$ and $10 \mathrm{~m} / \mathrm{min}$ respectively, while three depths of cut (i.e. 0.03 $\mathrm{mm}, 0.08 \mathrm{~mm}$, and $0.15 \mathrm{~mm}$ ) have been used in the trials.

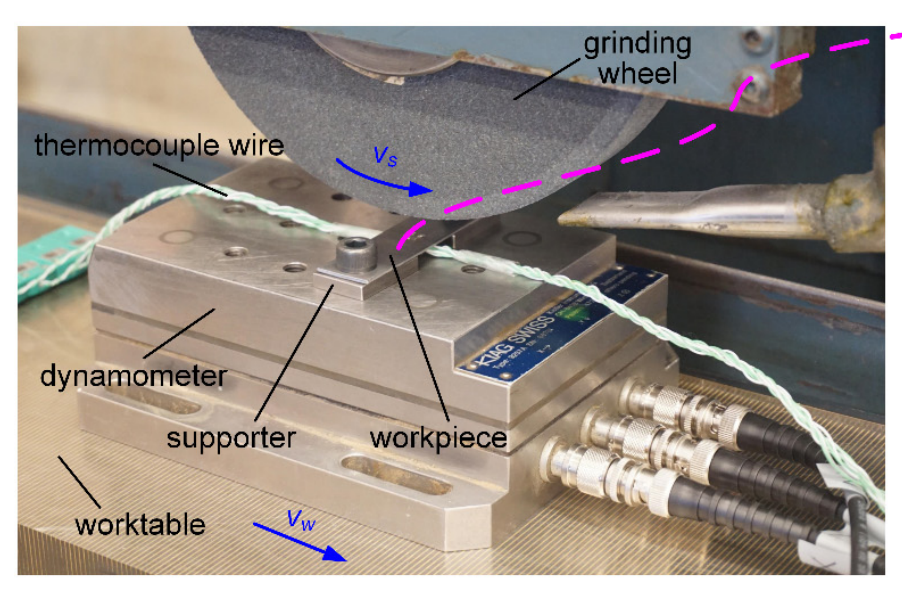

(a)

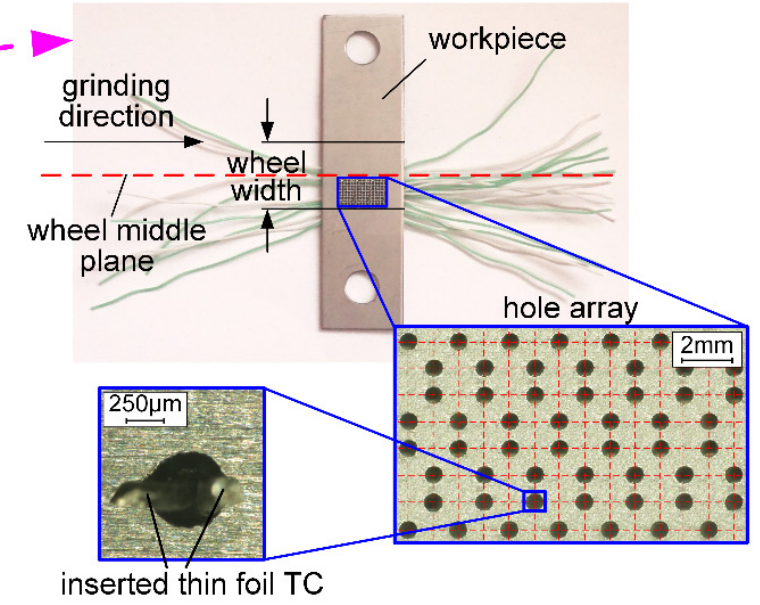

(b)

Fig.9 (a) Experiment setup employed in this study, and (b) the workpiece with an array of sacrificial two pole thermocouples

4.2 Grinding temperature measurement technique based on an array of sacrificial two pole thermocouples

To obtain 3D map of grinding temperature, thin foil thermocouples (TFTCs) have been inserted through the workpiece via an array of through holes produced on the workpiece (see Fig.9):

the array width (see Fig.10) has been designed to be $6 \mathrm{~mm}$, which was half of the wheel width 
as the thermal field could be considered symmetrical in reference to the wheel centerline;

0 the array length has been designed to be $12 \mathrm{~mm}$, which was close to the maximum wheelworkpiece contact length calculated according to Ref. [57] when using the employed grinding parameters;

$O$ the hole diameter (Fig.10) has been designed to be $0.5 \mathrm{~mm}$, which was smaller than the theoretical grain interval of $0.51 \mathrm{~mm}$ (experimentally proved to be equal to $2 d_{\text {gmax }}$ [9]) so that there is greater probability that each thermocouple could only capture temperature signals induced by one single grain at a time;

0 the neighboring hole distance has been designed to be $0.5 \mathrm{~mm}$, which was also smaller than the theoretical grain interval so that ideally at any moment at least one grain of two neighboring grains could be in contact with thermocouples.

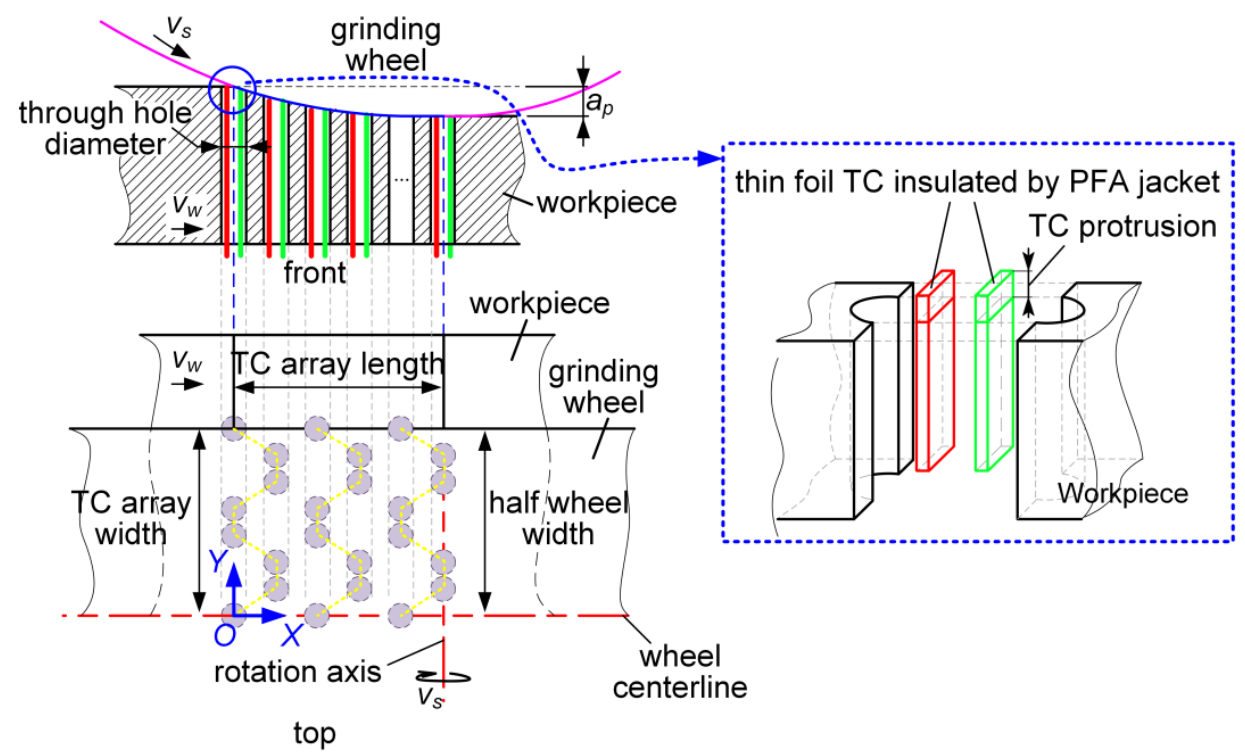

Fig.10 Schematics of the design of the thermocouple array (TC: thermocouple, PFA: perfluoroalkoxy resin)

To obtain fast response signals, K-type TFTCs (OMEGA 88000) thermocouples with the thickness of $0.15 \mathrm{~mm}$ insulated by perfluoroalkoxy resin jackets have been used in experiments while the thermocouple protrusion (see Fig.10) has been controlled within the range of 15-20 $\mu \mathrm{m}$. Before the experiments, the two thermocouple pole tips have been split apart forming an open circuit. Once the wheel passed the thermocouple, the materials of the two poles are smeared together thus, closing the circuit so that thermal signals could be captured. All the temperature data has been logged by three 16-channel data loggers (GW Model 100) at $100 \mathrm{kHz}$. The Kriging interpolation algorithm [62], widely employed in engineering to provide good linear unbiased prediction of intermediate values, has been used to obtain temperature maps. Please note each thermocouple in the following will be symbolised by its position in the defined coordinate XOY (marked blue in Fig.10).

\subsection{Experiment procedures}

The first set of trials has been performed to evaluate the feasibility of single TFTC technique until relatively robust signals have been obtained. The Energy Dispersive Spectrum (EDS) mapping of the formed measure junction (see Fig.11) could provide evidences for the formation of the measure junction. 


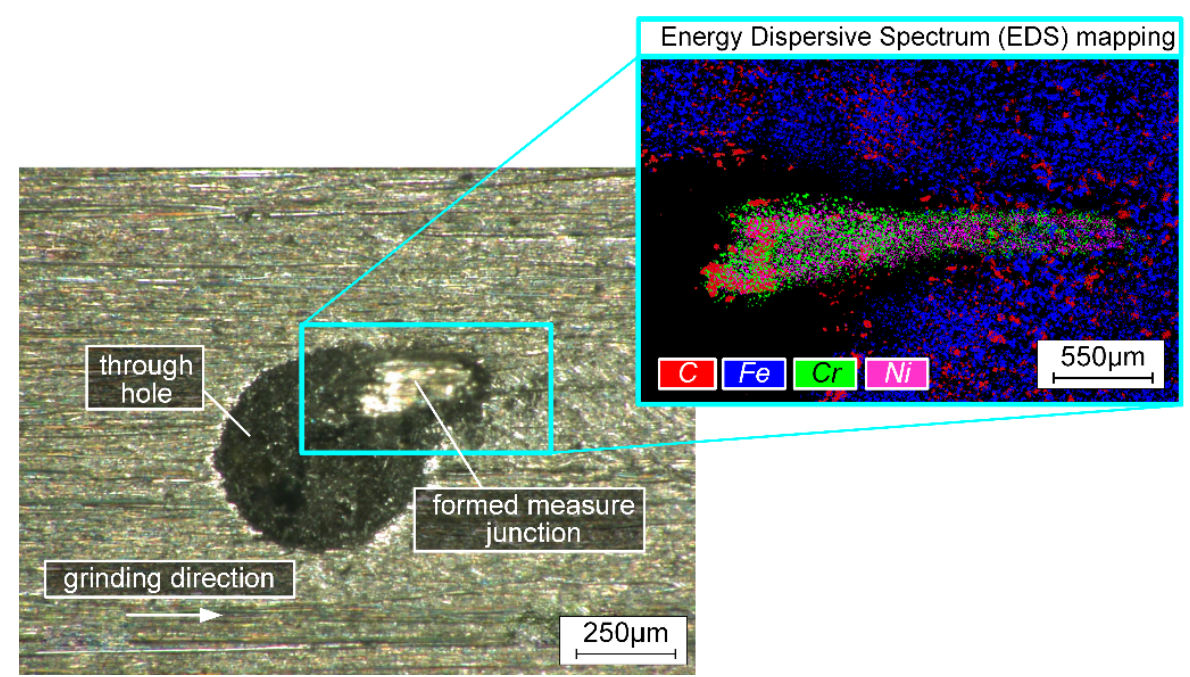

Fig.11 The formed measure junction of the thin foil thermocouple after the grinding trials and corresponding Energy Dispersive Spectrum (EDS) mapping (when $a_{p}$ of $80 \mu \mathrm{m}, v_{w}$ of $10 \mathrm{~m} / \mathrm{min}$, and $v_{s}$ of $26.9 \mathrm{~m} / \mathrm{s}$ )

Then, the second set of trials has been conducted to evaluate the measurement accuracy and the response time of the formed measure junction left on the workpiece surface. The standard K-type micro thermocouple (OMEGA 88303) has been carefully fixed close to the formed measure junction and then both thermcouples have been used to measure the temperature of a stable flame at the sampling rate $100 \mathrm{kHz}$. The maximum temperature measured by the formed junction was $795^{\circ} \mathrm{C}$, which was close to $801^{\circ} \mathrm{C}$ measured by the standard micro thermocouple, indicating the proposed technique could output high measurement accuracy. Also, the response time (the time it takes for the thermocouple to reach $63.2 \%$ of its maximum value [63]) of the formed junction was approximately $0.015 \mathrm{~ms}$, during which grains on the wheel surface could only move $0.015 \mathrm{~ms} \times 26.9$ $\mathrm{m} / \mathrm{s}=0.40 \mathrm{~mm}$, smaller than the theoretical grain interval $0.51 \mathrm{~mm}$, which means ideally the response time of the formed junction was fast enough to recognise each grain when grains pass the formed junction before the next grain engagement.

Based on above, the experimental setup was believed to be reliable and then the third set of trials has been performed to validate the proposed SGDTM.

\subsection{Methodology for model validations}

To verify SGDTM, grinding temperature obtained in experiments and calculated by SGDTM has been compared in terms of: (i) 1D temperature curves captured at specific locations within grinding zone, and (ii) 2D/3D temperature maps of the whole grinding zone.

For the first aspect, general comparisons of temperature curves have been first conducted by using the following five parameters:

O Maximum values of both the Upper Envelope (MUE in Fig.12, unit: ${ }^{\circ} \mathrm{C}$ ) and of the Lower Envelope (MLE in Fig.12, unit: ${ }^{\circ} \mathrm{C}$ ) of the temperature signals, which aims to compare the temperature curve shape along the vertical direction;

O Timespan of $80 \%$ of the MUE ( $t_{80}$ in Fig.12, unit: $\mathrm{ms}$ ), $60 \%$ of the MUE ( $t_{60}$ in Fig. 12 , unit: ms), and $40 \%$ of the MUE ( $t_{40}$ in Fig.12, unit: $\mathrm{ms}$ ), which aims to compare the temperature curve shape along the horizontal direction;

where upper and lower envelopes are defined as the curves that could outline the extremes of a 
known signal [64] could be obtained by using the envelope extraction algorithm [65].

Then detail comparisons of spike signals have been performed, as SGDTM aims to calculate grinding temperatures with detailed thermal information at grain scale. Four parameters in the whole temperature signal range and in the range of $t_{80}, t_{60}$, and $t_{40}$ have been defined to quantify the comparisons, which are:

Maximum and average amplitude of each spike signal $\left(A_{i}(i=1,2 \ldots)\right.$ in Fig.12), denoted as $A_{\max }$ and $A_{a v}$ (unit: ${ }^{\circ} \mathrm{C}$ );

O Maximum and average timespan of each spike signal $\left(S_{i}(i=1,2 \ldots)\right.$ in Fig.12), denoted as $S_{\max }$ and $S_{a v}$ (unit: $\mathrm{ms}$ );

where the spike signal has been defined as the peak signal $p_{n}$ which satisfies $p_{n}>p_{n-1}$ and $p_{n}>$ $p_{n+1}$ (see Fig.12).

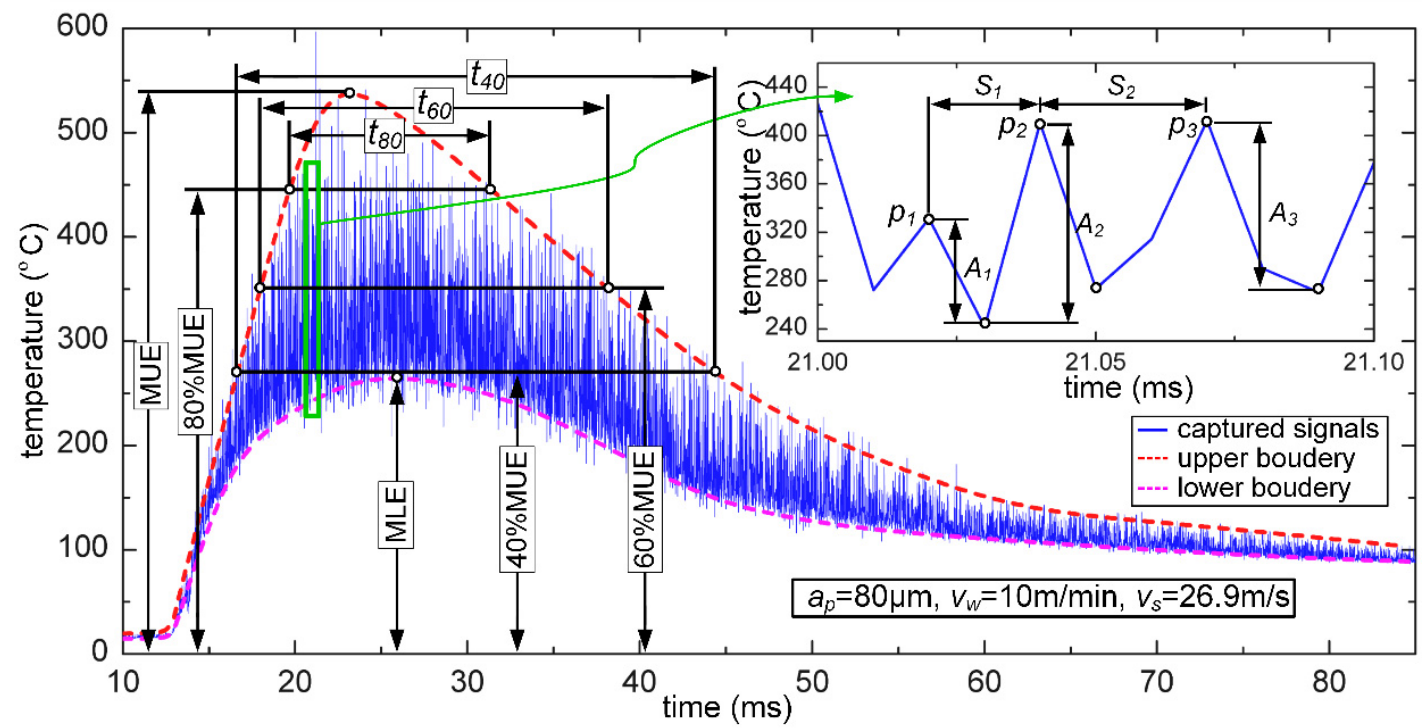

Fig.12 The parameters defined to quantitatively compare of the temperature signals: Maximum value of the Upper Envelope (MUE); Maximum value of the Lower Envelope (MLE), timespan of $80 \%$ of the MUE $\left(t_{80}\right), 60 \%$ of the MUE $\left(t_{60}\right)$, and $40 \%$ of the MUE $\left(t_{40}\right)$, average and maximum amplification of spike signals $\left(A_{\max }\right.$ and $\left.A_{a v}\right)$, and average and maximum timespan of spike signals $\left(S_{\max }\right.$ and $\left.S_{a v}\right)$

\section{Results and discussion - model validation}

$5.11 D$ temperature curves and spikes captured at specific locations within the wheel-workpiece contact zone

\subsubsection{General comparisons of temperature curves}

The comparison of temperature curves obtained in the experiments and calculated by SGDTM (see Fig.13) indicated that, generally, upper and lower envelopes of the theoretical and experimental signals are similar with each other. Among all 30 sets of comparisons, only the relative error of $t_{80}$ in Fig.13 (c) is beyond 10\%, which could be considered encouraging when considering the difference between the modeled and realistic random wheel topography has been controlled at the level of $10 \%$ (mentioned in Section 3.4.1). MUE is an important parameter that is related with the grinding burns, therefore MUE obtained by SGDTM are also compared with the one obtained by the classic 
analytical models given by Malkin et al. [9] (see MM in Fig.13). It could find that the maximum difference between the theoretical and Malkin et al.s' results is $7 \%$, indicating the accuracy of SGDTM. Malkin et al.'s model, however, cannot provide any temperature details (e.g. spike signal number, amplitude, time duration, etc.).

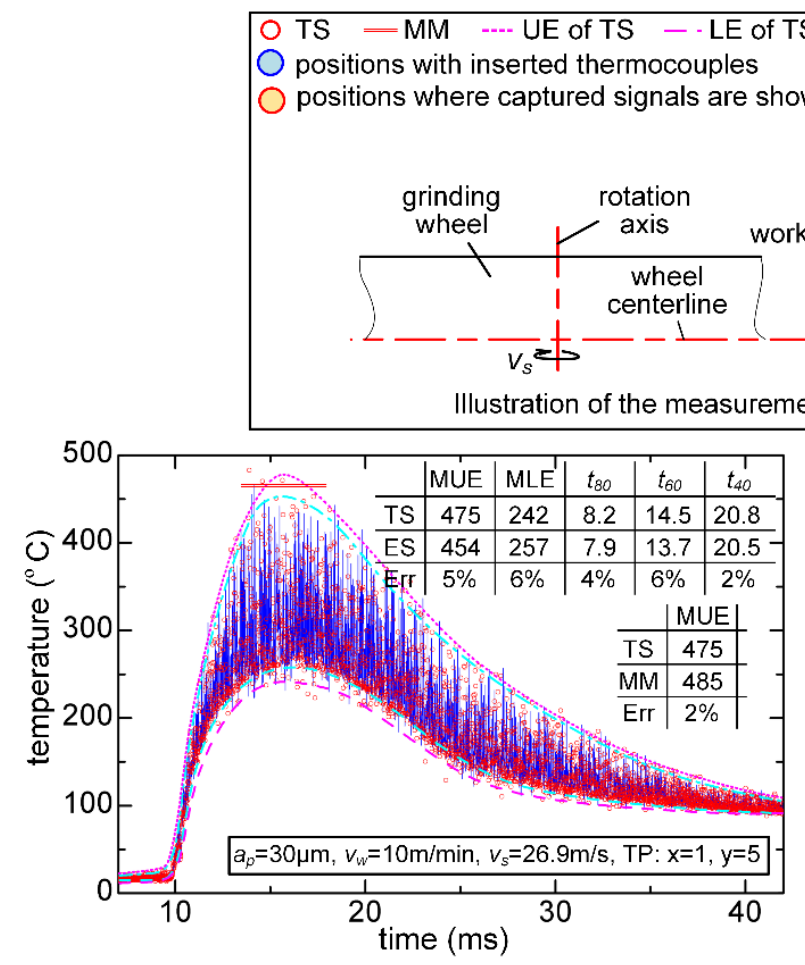

(a)

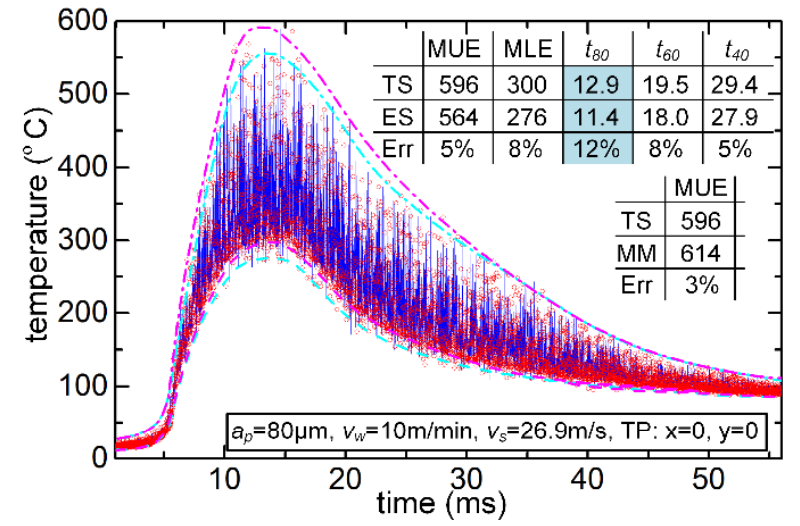

(c)

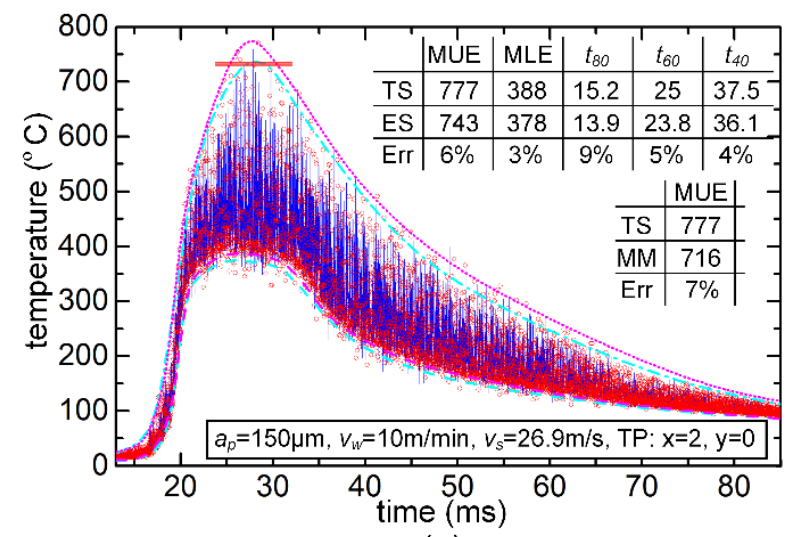

(e)

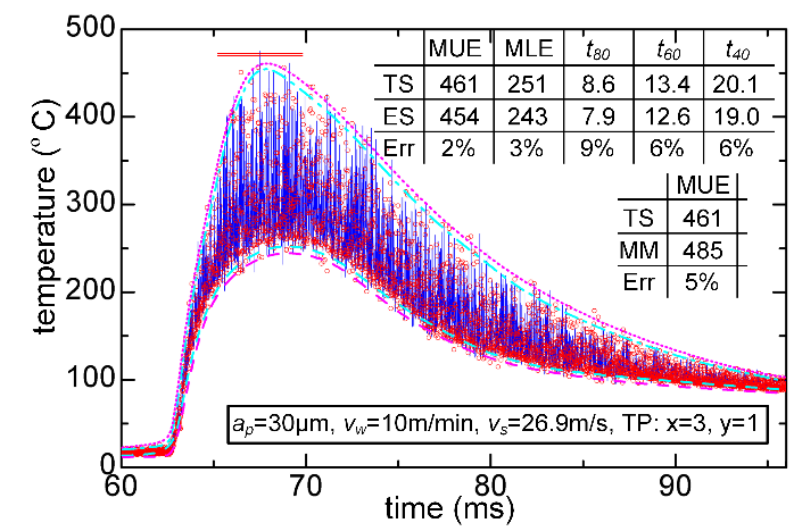

(b)

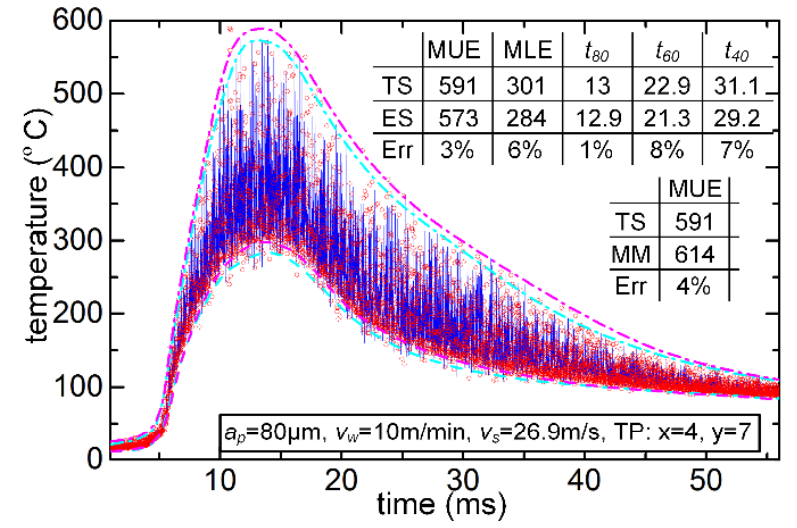

(d)

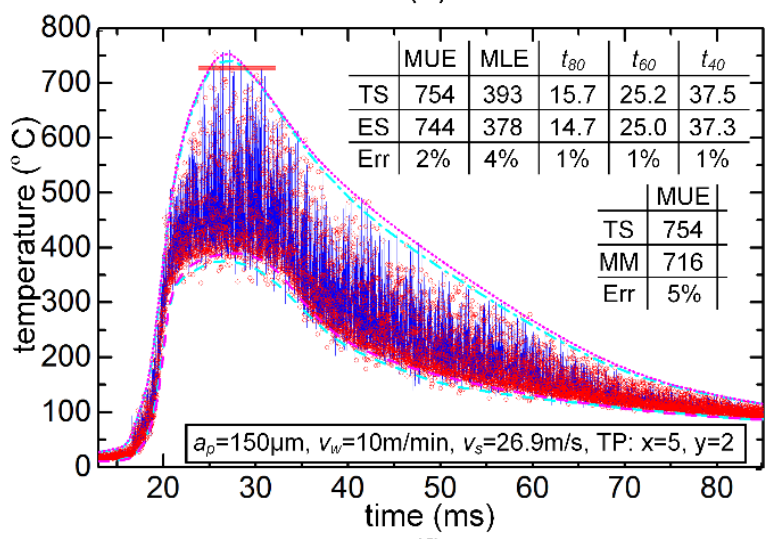

(f)

Fig.13 Comparison results of temperature signals captured in the experiments and theoretical calculations $\left(v_{w}\right.$ of $10 \mathrm{~m} / \mathrm{min}$ and $v_{w}$ of $26.9 \mathrm{~m} / \mathrm{s}$ are employed for all the comparison) when (a) $a_{p}$ of $30 \mu \mathrm{m}$ and thermocouple position (TP) of $(1,5)$, (b) $a_{p}$ of $30 \mu \mathrm{m}$ and TP of $(3,1)$, (c) $a_{p}$ of $80 \mu \mathrm{m}$ and TP of $(0,0)$, (d) $a_{p}$ of $80 \mu \mathrm{m}$ and TP of $(4,7),(\mathrm{e}) a_{p}$ of $150 \mu \mathrm{m}$ and 
TP of $(2,0)$ and (f) $a_{p}$ of $150 \mu \mathrm{m}$ and TP of $(5,2)$ (notations: TP: thermocouple position, TS: theoretical signal, UE: upper envelope, LE: lower envelope, ES: experimental signal, MM: MUE values obtained by Malkin et al.'s model [9], Err: relative error)

\subsubsection{Detailed comparison of spike signals}

Apart from the ability to describe general characteristics, the unique ability of SGDTM is to provide detailed features of each spike signal.

It could be seen from Table 2 that, the general difference between theoretical and experimental results varies in a relatively wide range. Among the 96 sets of data used for comparisons, only 11 sets show the relative errors higher than $20 \%$ (marked in dark blue in Table 2) while 22 sets lower than 5\% (marked in red in Table 2).

Table 2

Detailed comparison of the spike signals captured in the experiments and theoretical calculations (for constant $v_{w}$ of 10 $\mathrm{m} / \mathrm{min}$ and $v_{w}$ of $26.9 \mathrm{~m} / \mathrm{s}$ ) when $a_{p}$ of $30 \mu \mathrm{m}, 80 \mu \mathrm{m}$, and $150 \mu \mathrm{m}$ at the positions of $(1,5),(3,1),(0,0),(4,7),(2,0)$ and $(5,2)$ as shown in Fig.13 (a) (TP: thermocouple position, WR: whole range of the temperature signals, TS: theoretically generated signal, ES: experimental signal, Err: relative error)

\begin{tabular}{|c|c|c|c|c|c|c|c|c|c|c|c|c|c|c|c|c|c|c|}
\hline \multirow{2}{*}{$\begin{array}{c}a_{p} \\
(\mu \mathrm{m})\end{array}$} & \multirow{2}{*}{$\begin{array}{c}\mathrm{TP} \\
(\mathrm{mm})\end{array}$} & & \multicolumn{4}{|c|}{$A_{\max }\left({ }^{\circ} \mathrm{C}\right)$} & \multicolumn{4}{|c|}{$A_{a v}\left({ }^{\circ} \mathrm{C}\right)$} & \multicolumn{4}{|c|}{$S_{\max }\left(\times 10^{-3} \mathrm{~ms}\right)$} & \multicolumn{4}{|c|}{$S_{a v}\left(\times 10^{-3} \mathrm{~ms}\right)$} \\
\hline & & & WR & $t_{80}$ & $t_{60}$ & $t_{40}$ & WR & $t_{80}$ & $t_{60}$ & $t_{40}$ & WR & $t_{80}$ & $t_{60}$ & $t_{40}$ & WR & $t_{80}$ & $t_{60}$ & $t_{40}$ \\
\hline \multirow{6}{*}{30} & \multirow{3}{*}{$(1,3)$} & TS & 231 & 231 & 231 & 231 & 121 & 203 & 172 & 145 & 29 & 29 & 29 & 29 & 14 & 15 & 13 & 16 \\
\hline & & ES & 195 & 195 & 195 & 195 & 110 & 179 & 143 & 117 & 33 & 25 & 33 & 33 & 16 & 13 & 18 & 19 \\
\hline & & Err.(\%) & 18 & 18 & 18 & 18 & 10 & 13 & 20 & 24 & 12 & 16 & 12 & 12 & 13 & 15 & 28 & 16 \\
\hline & \multirow{3}{*}{$(4,1)$} & TS & 207 & 207 & 207 & 207 & 107 & 172 & 149 & 118 & 31 & 28 & 31 & 31 & 14 & 13 & 16 & 15 \\
\hline & & ES & 201 & 201 & 201 & 201 & 98 & 163 & 131 & 105 & 30 & 28 & 27 & 30 & 17 & 17 & 13 & 14 \\
\hline & & Err.(\%) & 3 & 3 & 3 & 3 & 9 & 6 & 14 & 12 & 3 & 0 & 15 & 3 & 18 & 24 & 23 & 7 \\
\hline \multirow{6}{*}{80} & \multirow{3}{*}{$(0,0)$} & TS & 365 & 365 & 365 & 365 & 177 & 302 & 247 & 185 & 28 & 27 & 26 & 28 & 19 & 16 & 18 & 13 \\
\hline & & ES & 387 & 387 & 387 & 387 & 193 & 322 & 279 & 225 & 26 & 26 & 26 & 26 & 15 & 17 & 18 & 18 \\
\hline & & Err.(\%) & 6 & 6 & 6 & 6 & 8 & 6 & 11 & 18 & 8 & 4 & 0 & 8 & 27 & 6 & 0 & 28 \\
\hline & \multirow{3}{*}{$(5,5)$} & TS & 341 & 341 & 341 & 341 & 160 & 289 & 238 & 171 & 28 & 25 & 28 & 28 & 14 & 12 & 13 & 15 \\
\hline & & ES & 331 & 331 & 331 & 331 & 166 & 281 & 230 & 183 & 27 & 25 & 27 & 27 & 16 & 17 & 15 & 18 \\
\hline & & Err.(\%) & 3 & 3 & 3 & 3 & 4 & 3 & 3 & 7 & 4 & 0 & 4 & 4 & 13 & 29 & 13 & 17 \\
\hline \multirow{6}{*}{150} & \multirow{3}{*}{$(2,0)$} & TS & 463 & 463 & 463 & 463 & 229 & 381 & 299 & 210 & 28 & 28 & 28 & 28 & 12 & 16 & 17 & 17 \\
\hline & & ES & 505 & 505 & 505 & 505 & 251 & 422 & 345 & 261 & 25 & 24 & 25 & 25 & 17 & 15 & 16 & 18 \\
\hline & & Err.(\%) & 8 & 8 & 8 & 8 & 9 & 10 & 13 & 20 & 12 & 17 & 12 & 12 & 29 & 7 & 6 & 6 \\
\hline & \multirow{3}{*}{$(9,2)$} & TS & 478 & 478 & 478 & 478 & 244 & 396 & 329 & 255 & 30 & 27 & 28 & 30 & 17 & 13 & 15 & 16 \\
\hline & & ES & 492 & 492 & 492 & 492 & 256 & 422 & 349 & 273 & 26 & 24 & 25 & 26 & 16 & 17 & 17 & 18 \\
\hline & & Err. $(\%)$ & 3 & 3 & 3 & 3 & 5 & 6 & 6 & 7 & 15 & 13 & 12 & 15 & 6 & 24 & 12 & 11 \\
\hline
\end{tabular}

For $A_{\max }$, which is related with maximum grain penetration depth, theoretical results show a reasonable consistency with experiments, and only at the thermocouple position $(1,3)$ it presents the relative error of $18 \%$. Rowe [1] gave the analytical derivation of $A_{\max }$ (i.e. Eq.(24)), according to which $A_{\max }$ in this case theoretically should be $387^{\circ} \mathrm{C}$, within the range of both the theoretical and experimental results.

$$
A_{\max }=\frac{q_{w c}}{q_{w c}+q_{s}} \cdot \tau v_{s} \frac{1}{\sqrt{k_{w} \rho C_{p}}} \sqrt{\frac{2 r_{e}}{v_{s}}}
$$

However, Rowe's equation could only predict the average $A_{\max }$ value, which means $387{ }^{\circ} \mathrm{C}$ calculated by Eq.(24) only gives a general indication about the temperature. In contrast with this, SGDTM could calculate more detailed $A_{\max }$ history nearly including full thermal information induced 
by each grain from grain engagement to disengagement, in which the influences of both wheel specification (e.g. grain size) and all machining parameters (i.e. $v_{s}, v_{w}$ and $a_{p}$ ) are also taken into consideration.

For the parameters $A_{a v}$ and $S_{\text {max }}$, SGDTM also presents similar results with the experimental ones. The big relative errors of more than $20 \%$ were found in reference to the comparisons of $S_{a v}$, which probably because the difference between random real and modeled grinding wheel topography, easily leads to much larger deviations when comparing the highly-localised and micro-scale parameters like $A_{\max , a v}$ and $S_{\max , a v}$. Even so, it could note that most theoretical $S_{a v}$ values are close to the ideal $S_{a v}$ value of $19.0 \mu$ s (calculated by dividing the ideal grain interval of $0.51 \mathrm{~mm}$ by the wheel speed of $26.9 \mathrm{~m} / \mathrm{s}$ ).

In fact, it would be challenging, if not impossible, to obtain the 1D theoretical temperature curve having exactly the same details at exactly the same grinding moment as the experimental one, although the wheel topography modeling procedures are consistent with the stochastic nature of the real topography. Given that the difference between experimental and modeled grinding wheel topography is around 10\% (see Fig.6), it would be reasonable to believe that the above comparisons would be enough not only to prove the accuracy of SGDTM to a certain extent, but also to show the possibility to model grinding temperature at grain scale.

\section{$5.22 D / 3 D$ temperature maps of the grinding zone}

In this section, the validation of SGDTM is conducted in terms of $2 \mathrm{D} / 3 \mathrm{D}$ temperature maps. For experiments, maps are obtained based on the thermal signals captured by thermocouples at specific locations (see Fig.14a), while theoretical maps are gained by performing the calculation as stated in Section 3 (see Fig.14b). Please note that, in order to compensate the error induced by the difference between the theoretical calculation resolution and the experimental thermocouple density, the theoretical temperature maps have been drawn by interpolating the theoretical temperature at exactly the same locations as the ones used in the experiments.

Fig.14 (a) presents the result when putting together each captured experimental signal within the time domain $t_{80} \quad\left(t_{80}\right.$ as defined in Section 5.1 and Fig.12). One important observation which could prove the assumption made in nearly all the previous studies was not appropriate enough is that, the maximum and average values of signals are varied along both the wheel direction and workpiece feed direction (see bottom diagrams in Fig.14a). This means heat fluxes along the wheel width direction and workpiece feed direction are neither uniformly-distributed nor continuous. Similar observations can also be achieved in the cross sections of the theoretical temperature map (see Fig.14b), which, to the best knowledge of the authors, is also the first calculated temperature mapping of the grinding zone up to now.

To quantitatively validate SGDTM, theoretical and experimental temperature domains are also compared in the form of contour maps (see Fig.15). It could find that, the theoretical and experimental temperature maps at two specific grinding moments are similar to each other. Among the 27 sets of the contour area comparisons in Fig.15 (a) and the 21 sets in Fig.15 (b), only the relative errors of 5 sets are beyond $10 \%$ separately in each diagram. It could be observed from Fig.15 that, with the grain engagement, the theoretical and experimental heat-affected zone (HAZ) shows similar sizes $\left(l_{H A Z}\right.$ in Fig.15). The highest temperature in the grinding zone at a same specific time is also comparable in value for both theoretical and experimental results (see Tmax theore, Tmax experi $_{t=83 \mu s}$, 
$\operatorname{Tmax}_{t=203 \mu s}^{\text {theore }}$ and $\operatorname{Tmax}_{t=203 \mu s}^{\text {experi }}$ in Fig.15) and the relative errors rates for Fig.15 (a) and (b) are $<1 \%$ and $2 \%$ respectively. All the above evidences could, to a large extent, prove the ability of SGDTM in describing the realistic temperature scenario.

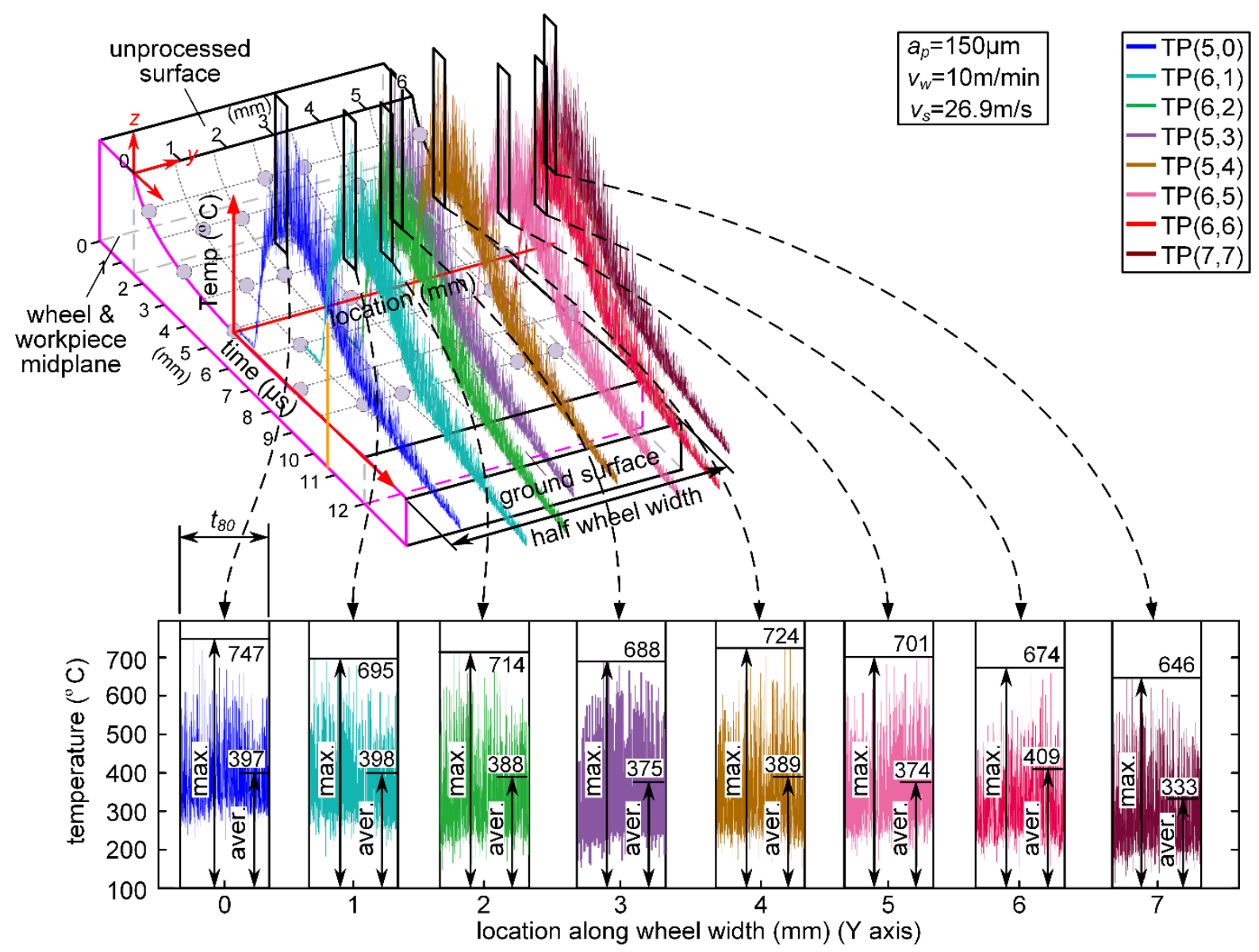

(a)

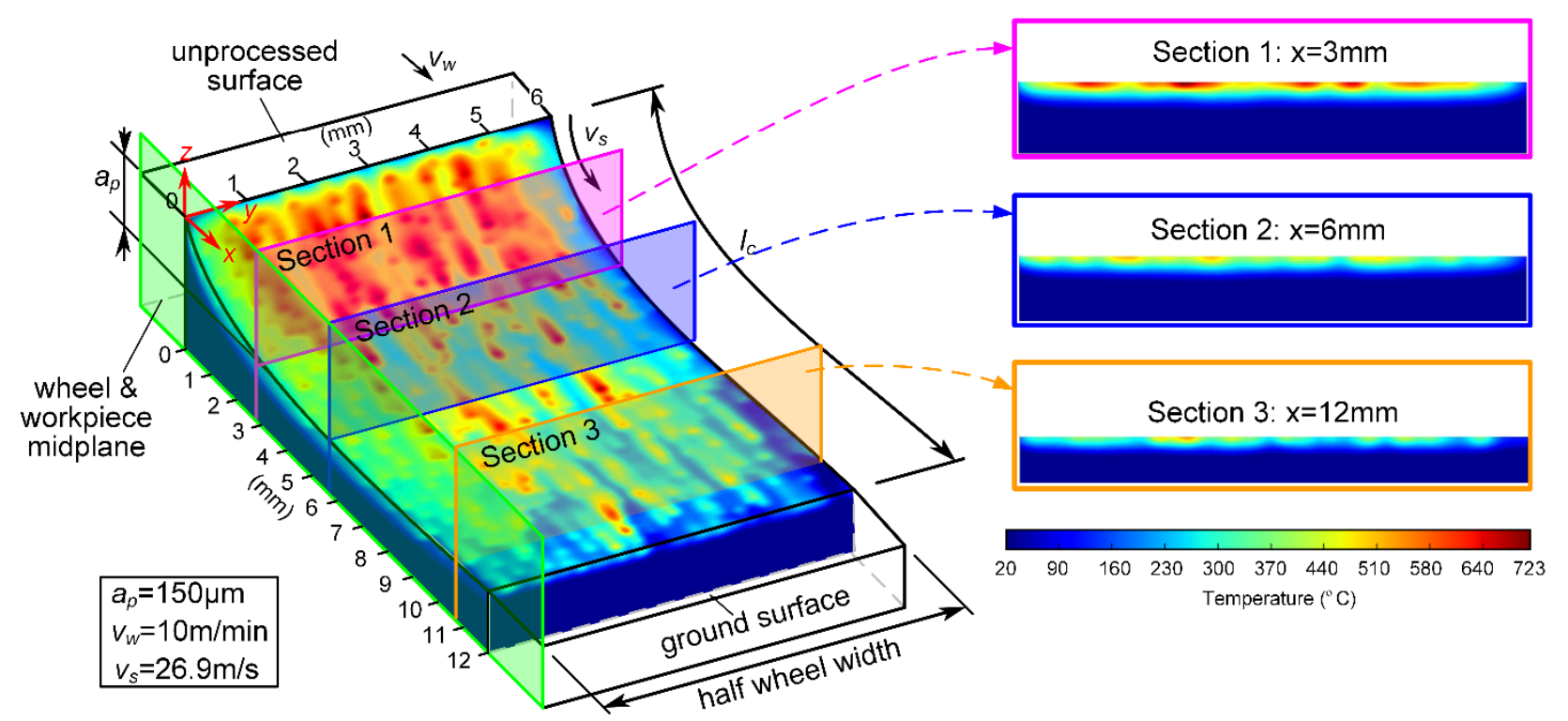

(b)

Fig.14 (a) Example of experimental results mapping the signals (within $t_{80}$ ) across the wheel width direction and (b) the theoretical 3D temperature map obtained by SGDTM considering different regimes of grain-workpiece interactions (including rubbing, ploughing and cutting) when $a_{p}$ of $150 \mu \mathrm{m}, v_{w}$ of $10 \mathrm{~m} / \mathrm{min}$, and $v_{s}$ of $26.9 \mathrm{~m} / \mathrm{s}\left(a_{p}\right.$ not to scale) 


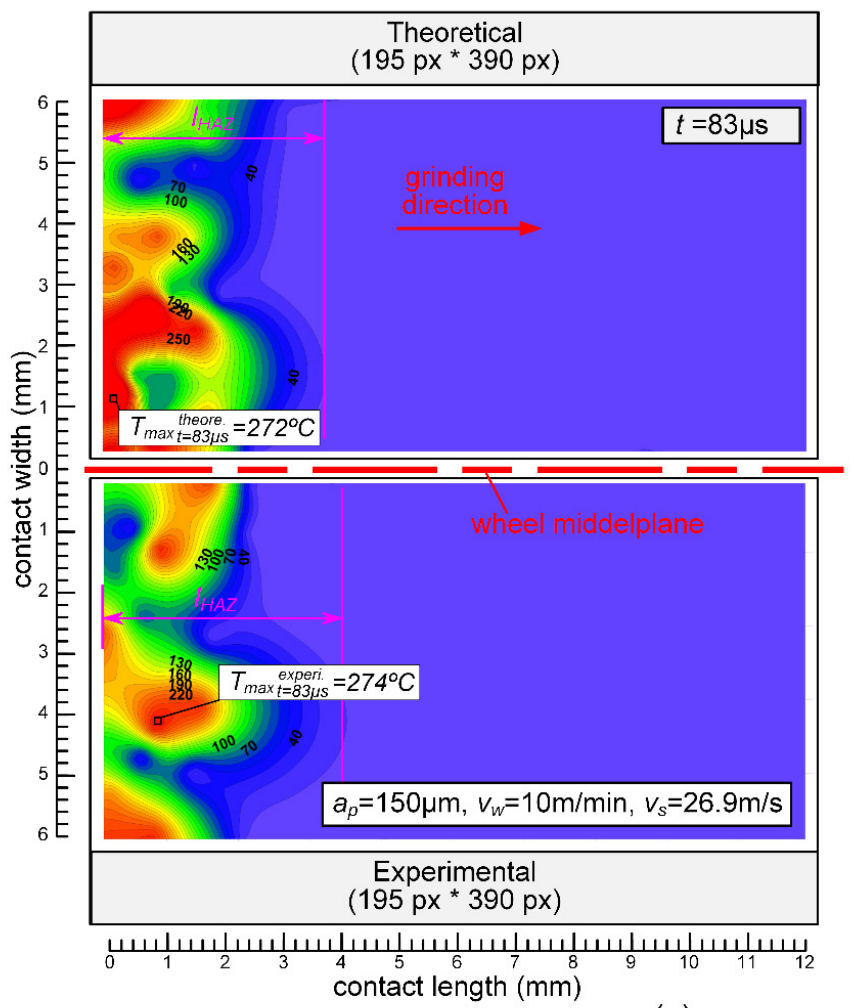

(a)

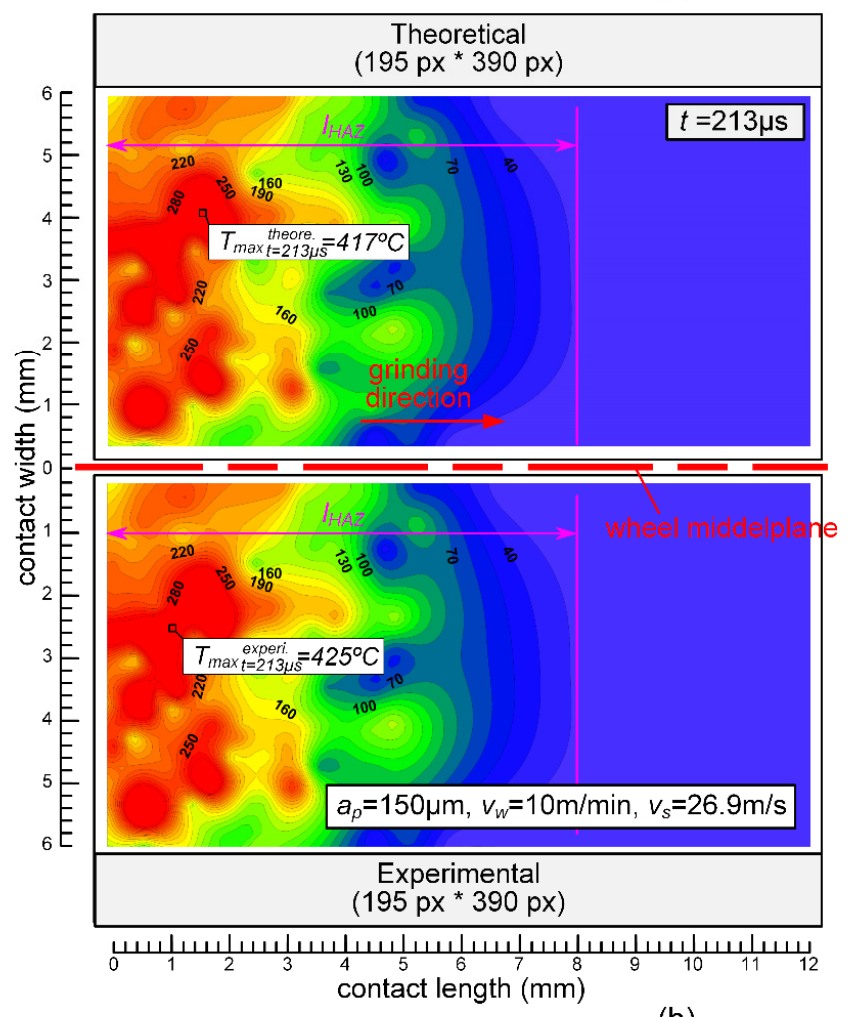

(b)

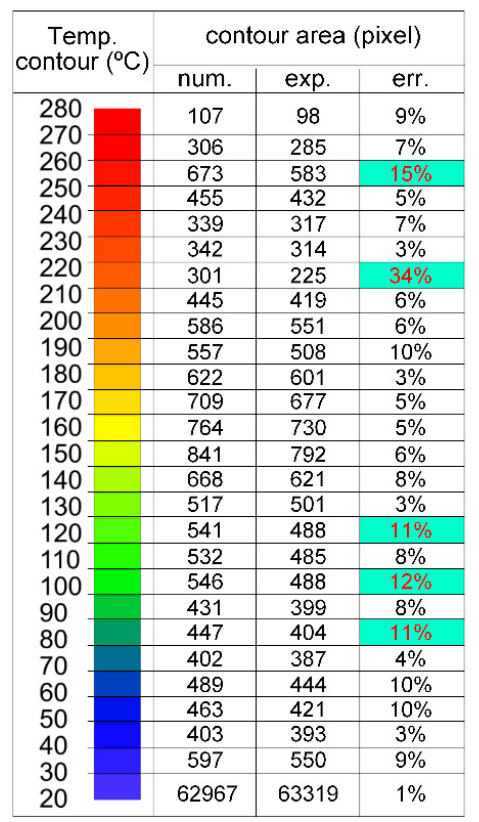

\begin{tabular}{|c|c|c|c|}
\hline \multirow{2}{*}{$\begin{array}{l}\text { Temp. } \\
\text { contour }\left({ }^{\circ} \mathrm{C}\right)\end{array}$} & \multicolumn{3}{|c|}{ contour area (pixel) } \\
\hline & num. & exp. & err. \\
\hline 430 & 269 & 295 & $10 \%$ \\
\hline 410 & 858 & 905 & $5 \%$ \\
\hline 390 & 1621 & 1745 & $8 \%$ \\
\hline 370 & 1749 & 1948 & $11 \%$ \\
\hline 350 & 1834 & 2041 & $11 \%$ \\
\hline 330 & 1703 & 1846 & $8 \%$ \\
\hline 310 & 1656 & 1733 & $5 \%$ \\
\hline 290 & 1803 & 1896 & $5 \%$ \\
\hline 270 & 1743 & 1819 & $4 \%$ \\
\hline 250 & 1798 & 1527 & $18 \%$ \\
\hline 230 & 1866 & 1903 & $2 \%$ \\
\hline 210 & 1985 & 1721 & $15 \%$ \\
\hline 190 & 1899 & 2056 & $8 \%$ \\
\hline 170 & 1843 & 1688 & $9 \%$ \\
\hline 150 & 1766 & 1627 & $9 \%$ \\
\hline 130 & 1859 & 1742 & $7 \%$ \\
\hline & 1788 & 1956 & $9 \%$ \\
\hline 90 & 1634 & 1420 & $15 \%$ \\
\hline 70 & 1539 & 1495 & $3 \%$ \\
\hline & 1920 & 1877 & $2 \%$ \\
\hline 30 & 1554 & 1419 & $10 \%$ \\
\hline 30 & 41063 & 41391 & $1 \%$ \\
\hline
\end{tabular}

Fig.15 Comparisons between theoretical and experimental temperature maps (in the form of contour maps) when (a) $t=83$ $\mu \mathrm{s}$ and $(\mathrm{b}) \mathrm{t}=213 \mu \mathrm{s}$

To show more advances of SGDTM, the theoretical calculation resolution is increased so that a temperature map with highly-localised information is achieved as seen in Fig.16, where even the temperature rise induced by individual grain could be recognised. These maps provides the possibility to explore the influence of the grit sizes, porosity, and even grit wear on the grinding 
temperature, and would be even more meaningful for the prevention of grinding damage like grinding burns, grinding annealing and rehardening.

From Fig.16, it could also clearly understand the scenario of grinding heat: the grinding zone is discretely heated by large numbers of point heat sources (cutting grains) with ultra-short time durations (ca. $19 \mu$ s referring to $S_{a v}$ in Section 5.1.2); each discrete heat source has little impact on the overall temperature rise of the ground workpiece surface, but large amounts of heat sources gradually raise the workpiece temperature. This also proves that having a full 3D map of the instantaneous temperatures and a powerful theoretical model to predict these at each abrasive gritworkpiece interface give a solid basis for more in-depth understanding of the governing phenomena than using the common approach depending on the single thermocouple technique.

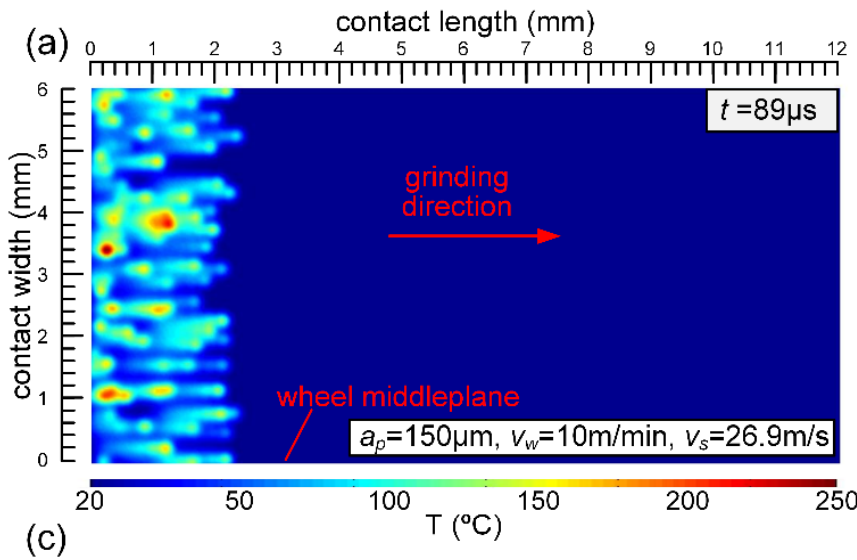

(b)
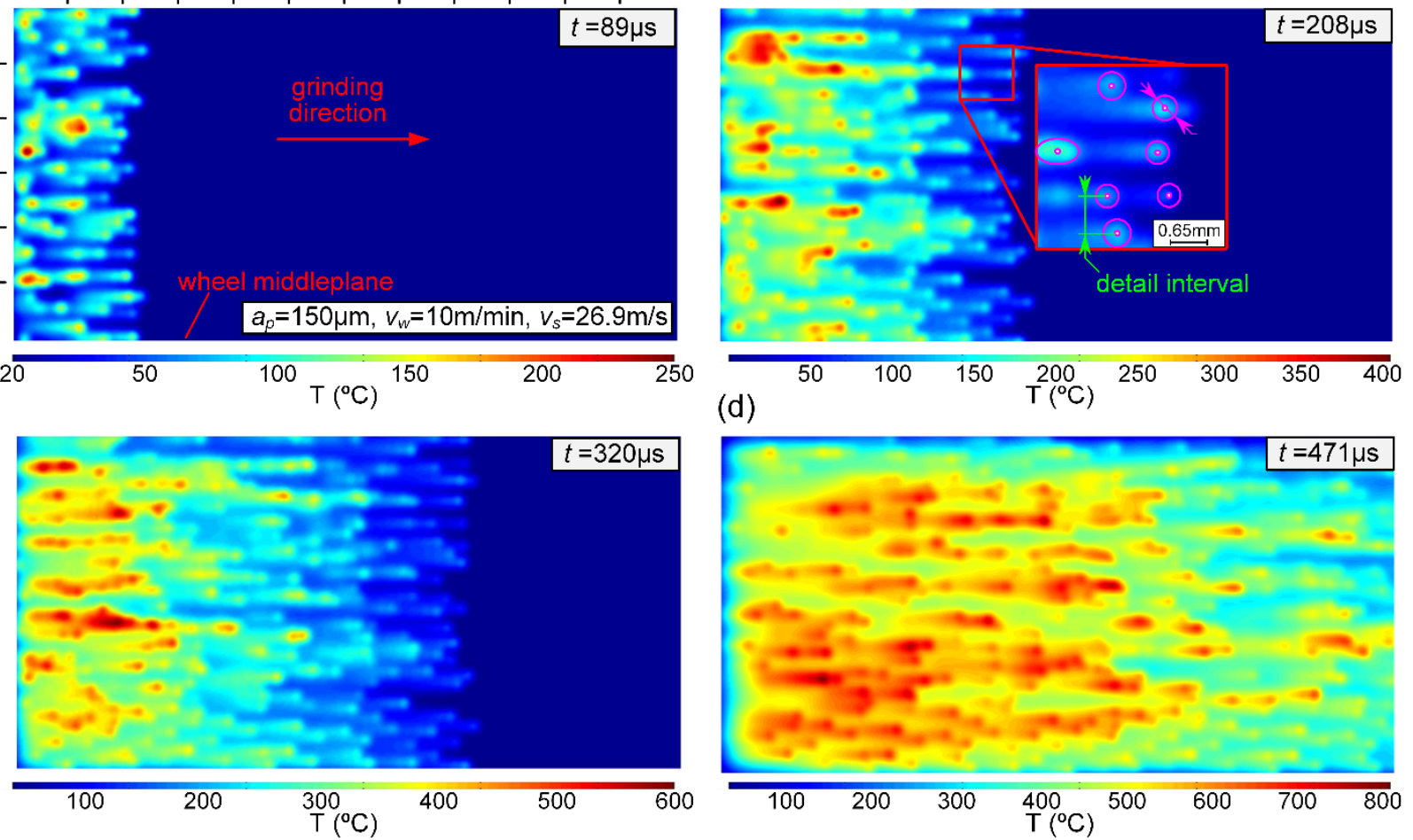

Fig.16 Grinding temperature maps when high theoretical calculation resolution at (a) $t=89 \mu \mathrm{s}$, (b) $t=208 \mu \mathrm{s}$, (c) $t=$ $320 \mu \mathrm{s}$ and $(\mathrm{d}) t=471 \mu \mathrm{s}$

A careful analysis of plots in Fig.16 also allows to comment that, the ideal density of the thermocouples (thermocouple number per unit area) that should be used to obtain good-quality temperature maps is $2.4 \mathrm{~mm}^{-2}$, because the thermal detail interval is approximately $0.65 \mathrm{~mm}$ (see in Fig.16b). This also explains why many details are lost in experimental maps (see bottom diagrams in Fig.15a, b): only the spots with the inserted thermocouples would have the temperature data while the temperature values of all the other locations could only be obtained by interpolation.

Therefore although the proposed thermocouple array technique provides the possibility to capture full grinding temperature mappings and, to the best knowledge of the authors, no publications suggested this technique, there are still practical challenges like the thermocouple sizes and the feasibility to produce closely-packed small-sized holes to insert thermocouples without changing the workpiece thermal properties, which might be the future research direction. 


\section{Conclusions}

In this paper, a stochastically grain-discretised temperature model (SGDTM) to predict the full 3D grinding temperature maps with highly-localised thermal information, even at the grain scale (i.e. the thermal impacts induced by each individual grain), has been proposed for the first time. Unlike any previous studies, the novelty of the proposed SGDTM is to model grinding temperature by individually calculating the heat generated by each grain at each grinding moment based on the determination of each grain-workpiece interaction regimes (including rubbing, ploughing and cutting). To validate the obtained temperature maps, a new methodological approach to capture 2D/3D temperature maps based on an array of sacrificial two-pole thermocouples have also been proposed, highly improving previous techniques based on single thermocouple. Based on the reported study, the following concluding remarks can be drawn:

The grinding temperature calculated by the proposed SGDTM shows reasonable agreements with the experimental one in terms of both the 1D temperature signals (among 30 sets of general comparisons one set showed relative errors of more than $10 \%$ while among 96 sets of detailed comparisons 11 sets showed relative errors of more than 20\%), and full 2D/3D temperature maps of grinding zone (among 48 sets of temperature contour area comparisons 10 sets showed relative error of more than $10 \%$ ), proving the feasibility and the accuracy of the proposed model;

O Based on both experimental and theoretical temperature maps, it can probably conclude that, the heat fluxes are neither uniformly-distributed along the wheel width direction nor continuous along the workpiece feed direction, indicating that the assumption made in most previous relevant studies have not captured all the phenomenological elements of the real wheelworkpiece interactions;

O For the first time, temperature maps visually present the scenario of grinding heat grinding heat: the grinding zone is discretely heated by large numbers of point heat sources (cutting grains) with ultra-short time durations; each discrete heat source has little impact on the overall temperature rise, but large amounts of heat sources gradually raise the workpiece temperature;

This provides a solid basis for more in-depth understanding of grinding heat, and, more importantly, gives the chance to guide industrial manufacture to avoid grinding damage (e.g. grinding burns, grinding annealing and rehardening);

O The proposed temperature map measurement technique based on thermocouple array also provides the possibility to experimentally capture grinding temperature maps, although the number of thermocouples implanted in the workpiece might become the bottleneck of this method when high map resolutions are required in the future. Promising applications of this technique in wet grinding, or even in all kinds of manufacture processes would probably enhance the existing understanding than using the common approach depending on the single thermocouple technique.

\section{References}

[1] W.B. Rowe, Principles of Modern Grinding Technology, USA: William Andrew Publishing, 2009.

[2] W. Rowe, S. Black, B. Mills, H. Qi, M. Morgan, Experimental investigation of heat transfer in grinding, CIRP Annals - Manufacturing Technology, 44 (1) (1995) 329-332. 
[3] S. Malkin, C. Guo, Thermal analysis of grinding, CIRP Annals-Manufacturing Technology, 56 (2) (2007) 760-782.

[4] R.S. Hahn. On the nature of the grinding process, in: Proceedings of the 3rd Machine Tool Design and Research Conference, Advances in Machine Tool Design and Research, 1962, pp. 129-154.

[5] J.C. Jaeger, Moving sources of heat and the temperature at sliding contacts, Proceedings of the Royal Society of New South Wales, 76 (1942) 203-225.

[6] H.S. Carslaw, J.C. Jaeger, Conduction of Heat in Solids, UK: Oxford University Press, 1959.

[7] L. Wang, Y. Qin, Z. Liu, P. Ge, W. Gao, Computer simulation of a workpiece temperature field during the grinding process, Proceedings of the Institution of Mechanical Engineers, Part B: Journal of Engineering Manufacture, 217 (7) (2003) 953-959.

[8] S. Malkin, C. Guo, Thermal analysis of grinding, CIRP Annals - Manufacturing Technology, 56 (2) (2007) 760-782.

[9] S. Malkin, C. Guo, Grinding technology: Theory and application of machining with abrasives, USA: McGraw-Hill, 2008.

[10] C. Guo, S. Malkin, Analysis of energy partition in grinding, Journal of Manufacturing Science and Engineering, 117 (1) (1995) 55-61.

[11] C. Guo, S. Malkin, Analysis of transient temperatures in grinding, Journal of Manufacturing Science and Engineering, 117 (4) (1995) 571-577.

[12] W.B. Rowe, Thermal analysis of high efficiency deep grinding, International Journal of Machine Tools and Manufacture, 41 (1) (2001) 1-19.

[13] B. Zhu, C. Guo, J.E. Sunderland, S. Malkin, Energy partition to the workpiece for grinding of ceramics, CIRP Annals - Manufacturing Technology, 44 (1) (1995) 267-271.

[14] S. Kohli, C. Guo, S. Malkin, Energy partition to the workpiece for grinding with aluminum oxide and CBN abrasive wheels, Journal of Manufacturing Science and Engineering, 117 (2) (1995) 160-168.

[15] Y. Ju, T. Farris, S. Chandrasekar, Theoretical analysis of heat partition and temperatures in grinding, Journal of tribology, 120 (4) (1998) 789-794.

[16] R. Snoeys, M. Maris, J. Peters, Thermally induced damage in grinding, CIRP Annals - Manufacturing Technology, 27 (2) (1978) 571-581.

[17] W.B. Rowe, T. Jin, Temperatures in high efficiency deep grinding (HEDG), CIRP Annals Manufacturing Technology, 50 (1) (2001) 205-208.

[18] T. Jin, W.B. Rowe, D. McCormack, Temperatures in deep grinding of finite workpieces, International Journal of Machine Tools and Manufacture, 42 (1) (2002) 53-59.

[19] T. Tawakoli, C.G. Barrett, High-efficiency deep grinding: Technology, process planning and economic application, USA: Wiley, 1993.

[20] W. Rowe, M. Morgan, A. Batako, T. Jin, Energy and temperature analysis in grinding, WIT Transactions on Engineering Sciences, 44 (2003) 1-23.

[21] T. Jin, G.Q. Cai, Analytical thermal models of oblique moving heat source for deep grinding and cutting, Journal of Manufacturing Science and Engineering, 123 (2) (2000) 185-190.

[22] N.R. DesRuisseaux, R.D. Zerkle, Temperature in semi-infinite and cylindrical bodies subjected to moving heat sources and surface cooling, ASME transactions journal of heat transfer, 92 (3) (1970) 456-464.

[23] S. Malkin, N.H. Cook, The wear of grinding wheels: Part 2 - fracture wear, Journal of Engineering for Industry, 93 (4) (1971) 1129-1133.

[24] C. Guo, S. Malkin, Analytical and experimental investigation of burnout in creep-feed grinding, CIRP Annals - Manufacturing Technology, 43 (1) (1994) 283-286.

[25] Z.B. Hou, R. Komanduri, On the mechanics of the grinding process, Part III-thermal analysis of the 
abrasive cut-off operation, International Journal of Machine Tools and Manufacture, 44 (2-3) (2004) 271-289.

[26] M. Mahdi, L. Zhang, The finite element thermal analysis of grinding processes by ADINA, Computers \& Structures, 56 (2) (1995) 313-320.

[27] D. Biermann, M. Schneider, Modeling and simulation of workpiece temperature in grinding by finite element analysis, Machining Science and Technology, 1 (2) (1997) 173-183.

[28] P. Moulik, H. Yang, S. Chandrasekar, Simulation of thermal stresses due to grinding, International Journal of Mechanical Sciences, 43 (3) (2001) 831-851.

[29] H. Hamdi, H. Zahouani, J.-M. Bergheau, Residual stresses computation in a grinding process, Journal of materials processing technology, 147 (3) (2004) 277-285.

[30] B. Shen, G. Xiao, C. Guo, S. Malkin, A.J. Shih, Thermocouple fixation method for grinding temperature measurement, Journal of Manufacturing Science and Engineering, 130 (5) (2008) 051014.

[31] J. Li, J.C.M. Li, Temperature distribution in workpiece during scratching and grinding, Materials Science and Engineering: A, 409 (1-2) (2005) 108-119.

[32] H.-J. Kim, N.-K. Kim, J.-S. Kwak, Heat flux distribution model by sequential algorithm of inverse heat transfer for determining workpiece temperature in creep feed grinding, International Journal of Machine Tools and Manufacture, 46 (15) (2006) 2086-2093.

[33] H.W. Park, S.Y. Liang, Force modeling of microscale grinding process incorporating thermal effects, The International Journal of Advanced Manufacturing Technology, 44 (5) (2008) 476-486.

[34] A.D. Batako, W.B. Rowe, M.N. Morgan, Temperature measurement in high efficiency deep grinding, International Journal of Machine Tools and Manufacture, 45 (11) (2005) 1231-1245.

[35] C. Mao, H. Zou, Y. Huang, Y. Li, Z. Zhou, Analysis of heat transfer coefficient on workpiece surface during minimum quantity lubricant grinding, The International Journal of Advanced Manufacturing Technology, 66 (1-4) (2013) 363-370.

[36] M. Morgan, L. Barczak, A. Batako, Temperatures in fine grinding with minimum quantity lubrication (MQL), The International Journal of Advanced Manufacturing Technology, 60 (9-12) (2012) 951-958.

[37] X. Xu, Y. Yu, H. Xu, Effect of grinding temperatures on the surface integrity of a nickel-based superalloy, Journal of materials processing technology, 129 (1) (2002) 359-363.

[38] G. Xie, H. Huang, An experimental investigation of temperature in high speed deep grinding of partially stabilized zirconia, International Journal of Machine Tools and Manufacture, 48 (14) (2008) 1562-1568.

[39] O. Nosko, T. Nagamine, A.L. Nosko, A.M. Romashko, H. Mori, Y. Sato, Measurement of temperature at sliding polymer surface by grindable thermocouples, Tribology International, 88 (2015) 100-106.

[40] A. Lefebvre, P. Vieville, P. Lipinski, C. Lescalier, Numerical analysis of grinding temperature measurement by the foil/workpiece thermocouple method, International Journal of Machine Tools and Manufacture, 46 (14) (2006) 1716-1726.

[41] A. Lefebvre, F. Lanzetta, P. Lipinski, A. Torrance, Measurement of grinding temperatures using a foil/workpiece thermocouple, International Journal of Machine Tools and Manufacture, 58 (2012) 1 10.

[42] H.K. Tönshoff, T. Friemuth, J.C. Becker, Process Monitoring in Grinding, CIRP Annals - Manufacturing Technology, 51 (2) (2002) 551-571.

[43] T. Ueda, K. Yamada, T. Sugita, Measurement of grinding temperature of ceramics using infrared radiation pyrometer with optical fiber, Journal of Engineering for Industry, 114 (3) (1992) 317-322.

[44] T. Ueda, A. Hosokawa, A. Yamamoto, Measurement of grinding temperature using infrared radiation pyrometer with optical fiber, Journal of Manufacturing Science and Engineering, 108 (4) (1986) 247251.

[45] T. Ueda, H. Tanaka, A. Torii, T. Matsuo, Measurement of grinding temperature of active grains using 
infrared radiation pyrometer with optical fiber, CIRP Annals - Manufacturing Technology, 42 (1) (1993) 405-408.

[46] T. Ueda, M. Sato, T. Sugita, K. Nakayama, Thermal behaviour of cutting grain in grinding, CIRP Annals - Manufacturing Technology, 44 (1) (1995) 325-328.

[47] J. Hwang, S. Kompella, S. Chandrasekar, T.N. Farris, Measurement of temperature field in surface grinding using infra-red (IR) imaging system, Journal of tribology, 125 (2) (2003) 377-383.

[48] A.-M.O. Mohamed, A. Warkentin, R. Bauer, Variable heat flux in numerical simulation of grinding temperatures, The International Journal of Advanced Manufacturing Technology, 63 (5) (2012) 549554.

[49] A. Brosse, P. Naisson, H. Hamdi, J. Bergheau, Temperature measurement and heat flux characterization in grinding using thermography, Journal of materials processing technology, 201 (1) (2008) 590-595.

[50] D. Anderson, A. Warkentin, R. Bauer, Comparison of numerically and analytically predicted contact temperatures in shallow and deep dry grinding with infrared measurements, International Journal of Machine Tools and Manufacture, 48 (3-4) (2008) 320-328.

[51] D. Anderson, A. Warkentin, R. Bauer, Experimental validation of numerical thermal models for dry grinding, Journal of materials processing technology, 204 (1-3) (2008) 269-278.

[52] S. Malkin, Thermal aspects of grinding: Part 2 - surface temperatures and workpiece burn, Journal of Engineering for Industry, 96 (4) (1974) 1184-1191.

[53] H.S. Carslaw, J.C. Jaeger, Conduction of heat in solids, UK: Clarendon Press, 1986.

[54] J. Goldak, A. Chakravarti, M. Bibby, A new finite element model for welding heat sources, Metallurgical Transactions B, 15 (2) (1984) 299-305.

[55] J. Mazumder, W. Steen, Heat transfer model for CW laser material processing, Journal of Applied Physics, 51 (2) (1980) 941-947.

[56] S. Ghosh, A. Chattopadhyay, S. Paul, Modelling of specific energy requirement during high-efficiency deep grinding, International Journal of Machine Tools and Manufacture, 48 (11) (2008) 1242-1253.

[57] W.B. Rowe, M.N. Morgan, H.S. Qi, H.W. Zheng, The Effect of Deformation on the Contact Area in Grinding, CIRP Annals - Manufacturing Technology, 42 (1) (1993) 409-412.

[58] I.D. Marinescu, M.P. Hitchiner, E. Uhlmann, W.B. Rowe, I. Inasaki, Handbook of machining with grinding wheels, USA: CRC Press, 2006.

[59] V. Singh, P.V. Rao, S. Ghosh, Development of specific grinding energy model, International Journal of Machine Tools and Manufacture, 60 (2012) 1-13.

[60] Z.B. Hou, R. Komanduri, On the mechanics of the grinding process-Part I. Stochastic nature of the grinding process, International Journal of Machine Tools and Manufacture, 43 (15) (2003) 1579-1593.

[61] Y. Liu, A. Warkentin, R. Bauer, Y. Gong, Investigation of different grain shapes and dressing to predict surface roughness in grinding using kinematic simulations, Precision Engineering, 37 (3) (2013) 758764.

[62] F. Trochu, A contouring program based on dual kriging interpolation, Engineering with computers, 9 (3) (1993) 160-177.

[63] D.D. Pollock, Thermocouples: Theory and properties, UK: Taylor \& Francis, 1991.

[64] J. C. Richard Johnson, W.A. Sethares, A.G. Klein, Software receiver design: Build your own digital communication system in five easy steps, UK: Cambridge University Press, 2011.

[65] S. Choi, Z. Jiang, Comparison of envelope extraction algorithms for cardiac sound signal segmentation, Expert Systems with Applications, 34 (2) (2008) 1056-1069. 
On a stochastically grain-discretised model for 2D/3D temperature mapping prediction in grinding

$$
\text { Hao Nan Li a, b, Dragos Axinte a, c, }{ }^{*}
$$

a Machining and Condition Monitoring Group, Faculty of Engineering, University of Nottingham, Nottingham NG7 2RD, United Kingdom

b School of Mechanical Engineering and Automation, Northeastern University, Shenyang 110819, P. R. China

${ }^{c}$ Department of Mechanical, Materials and Manufacturing Engineering, The University of Nottingham Ningbo, China

* Corresponding author.

Tel.: +44 (0) 1159514117 ;

E-mail address: Dragos.axinte@nottingham.ac.uk (D. A. Axinte). 